MARIA FERNANDA PEREIRA LOUREIRO

Indução do estro por implante de melatonina em ovinos da raça Suffolk

São Paulo

2003 


\section{Indução do estro por implante de melatonina em ovinos da raça Suffolk}

Dissertação apresentada ao Programa de Pósgraduação em Reprodução Animal da Faculdade de Medicina Veterinária e Zootecnia da Universidade de São Paulo para a obtenção do título de Mestre em Medicina Veterinária

\section{Departamento:}

Reprodução Animal

Área de Concentração:

Reprodução Animal

Orientadora:

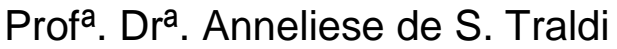

São Paulo 
Autorizo a reprodução parcial ou total desta obra, para fins acadêmicos, desde que citada a fonte.

DADOS INTERNACIONAIS DE CATALOGAÇÃO-NA-PUBLICAÇÃO

(Biblioteca da Faculdade de Medicina Veterinária e Zootecnia da Universidade de São Paulo)

T.1325 Loureiro, Maria Fernanda Pereira

FMVZ Indução do estro por implante de melatonina em ovinos da raça Suffolk / Maria Fernanda Pereira Loureiro. - São Paulo : M. F. P. Loureiro, 2003.

$68 \mathrm{f}$. : il.

Dissertação (mestrado) - Universidade de São Paulo. Faculdade de Medicina Veterinária e Zootecnia. Departamento de Reprodução Animal, 2003.

Programa de Pós-graduação: Reprodução Animal.

Área de concentração: Reprodução Animal.

Orientador: Profa. Dra. Anneliese de S. Traldi.

1. Hormônios. 2. Ovinos. 3. Estro animal. 4. Fotoperiodismo. 5. Pineal animal. I. Título. 


\section{UNIVERSIDADE DE SÃO PAULO \\ Faculdade de Medicina Veterinária e Zootecnia \\ Cidade Universitária "Armando de Salles Oliveira"}

\section{Comissão Bioética}

\section{CERTIFICADO}

Certificamos que o Projeto intitulado

"Desestacionalização do ciclo estral de ovelhas da raça Suffolk através do uso de implantes subcutâneos de melatonina", Protocolo $\mathrm{n}^{\circ}$ 126/2002, sob a responsabilidade da $\operatorname{Prof}^{\mathrm{a}} \operatorname{Dr}^{\mathrm{a}}$ Anneliese de Souza Traldi, está de acordo com os princípios éticos de experimentação animal da Comissão de Bioética da Faculdade de Medicina Veterinária e Zootecnia da Universidade de São Paulo e foi aprovado pela referida Comissão, em sessão de 05/06/2002.

(We certify that the Research "Subcutaneous implant of melatonin in Suffolk ewe " protocol number 126/2002, under the responsability of Prof $^{a}$ Dr $^{a}$ Anneliese de Souza Traldi, agree with Ethical Principles in Animal Research adopted by Bioethic Commission of the Faculty of Veterinary Medicine and Zootechny of University of São Paulo and was approved in 06/05/2002 meeting.

São Paulo, 05 de junho de 2002

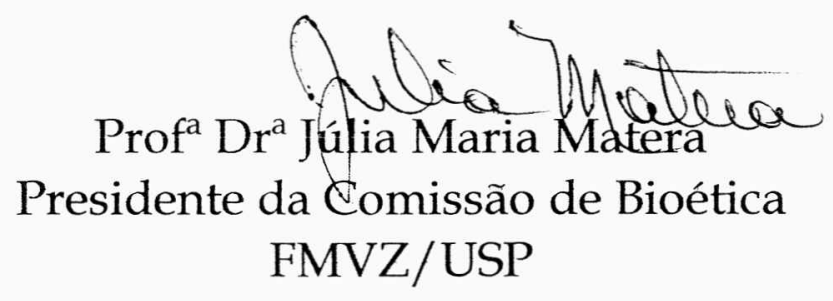




\section{FOLHA DE AVALIAÇÃO}

Nome do autor: LOUREIRO, Maria Fernanda Pereira

Título: Indução do estro por implante de melatonina em ovinos da raça Suffolk

Dissertação apresentada ao Programa de Pósgraduação em Reprodução Animal da Faculdade de Medicina Veterinária e Zootecnia da Universidade de São Paulo para a obtenção do título de Mestre em Medicina Veterinária

Data:

Banca Examinadora

Prof. Dr.

Assinatura:

Prof. Dr.

Assinatura:

Prof. Dr.

Assinatura:
Instituição:

Julgamento:

Instituição:

Julgamento:

Instituição:

Julgamento: 
Ao meu pai, saudoso João Bosco e a minha querida mãe, que sempre nos incentivaram a viver e conquistar nossos ideais, e por nunca terem medido esforços para nossa criação e educação.

Ao Ricardo, meu grande amor. 


\section{AGRADECIMENTOS}

À Prof ${ }^{a}$. Drª . ANNELIESE S. TRALDI (KIKY) pela orientação e oportunidades.

Ao Prof. ED HOFFMANN MADUREIRA pelo primeiro contato com o Departamento e pela sua disposição em nos ajudar e compartilhar seus conhecimentos.

Ao Prof. Dr. JOSÉ ANTÔNIO VISINTIN pelo exemplo de firmeza, comando e apoio, sempre.

Ao Prof. Dr. RUBENS PAES DE ARRUDA pelas cessões concedidas e conversas de conterrâneos.

Ao Prof. Dr. RENATO CAMPANARUT BARNABE, pela oportunidade e atenção dedicada ao pós-graduandos.

Ao Prof. Dr. PAULO H. MAZZA RODRIGUES pela sua inestimável ajuda na análise estatística.

À minha mãe FÁTIMA, meu pai JOÃO BOSCO e meus irmãos, JU E JOÃO, por toda a nossa vida...juntos!!!

Ao meu querido e amado RICARDO pela cumplicidade, compreensão, convivência e por ser um exemplo de coragem e abnegação.

Às meninas e médicas veterinárias: ADRIANA CAPEZZUTO (DRIZINHA), ALESSANDRA BRANDÃO (ALEZINHA), ANA RITA COUTINHO (NANI), pela amizade intensa, imensa ajuda nas coletas de dados e infindáveis conversas e risos.

Ao Sr. LUIS FERNANDO GOTTARDI e seu irmão TUCA por ter aberto as portas de sua propriedade "Cabanha Araçá".

Aos funcionários da Cabanha Araçá: ROMILDO, CHIQUINHO E ZINHA pela ajuda e dedicação.

Às amigas PAULINE, mais uma vez ADRIANA E NANI, sem esquecer da Maria por terem me acolhido em seus lares.

Às amigas CARLINHA CELEGHINI, GRAZIELA PORTELLA E CLÁUDIA BERTAN, pelas conversas, trocas de idéias e amparo a qualquer hora. 
Aos amigos que passaram e aos que continuam no CBRA: ISABEL BARBOSA, ANINHA MAZORRA, FERNANDA CIRILLO, VANESSA STORILLO (CLÍ), LUÍS (WOBAT), KÁTIA MIZUTA, GUTINHO, RODRIGO SANTANA, PÉRCIO, ALEMÃO, ANA KARINA, ANA PAULA MANTOVANI, PAOLA, ROGÉRIO GAMA, NÉLCIO, MENININHO, LEC, LÍLIAN, MÁRCIO DE CARLI, JOSÉ MARIA pelo convívio.

Aos amigos do Capril da PCAPS: ADEMIR, MARCOS, ZEZINHO e JOÃO pelo auxílio.

À VIVIANE MATTOS que me acolheu em muitos momentos difíceis e estava presente no momento mais feliz da minha vida!

À todos os professores e alunos de pós-graduação e funcionários do Departamento de Reprodução Animal.

Às secretárias do VRA e da pós-graduação, sempre prestimosas.

À CAPES pela bolsa de mestrado concedida pelo período de 18 meses e descontinuada sem necessidade.

À Ceva Santé Animale pela cessão dos implantes de melatonina.

À todos vocês meu muito obrigada!!! 
Somos aprendizes de uma arte na qual ninguém se torna mestre.

Ernest Hemingway (1898-1961) 


\section{RESUMO}

LOUREIRO, M. F. P. Indução do estro por implante de melatonina em ovinos da raça Suffolk. [Oestrus induction with melatonin implant in Suffolk]. 2003. $68 \mathrm{f}$. Dissertação (Mestrado em Medicina Vererinária) - Faculdade de Medicina Veterinária e Zootecnia, Universidade de São Paulo, São Paulo, 2003.

Durante o início da primavera, na região oeste do Estado de São Paulo, fêmeas Suffolk ( $n=91)$ foram tratadas com 1 (1M) ou 2 implantes (2M) subcutâneos de 18 mg de melatonina (Mélovine), acompanhadas por um lote controle (C), e submetidas ao efeito macho por rufiões, 42 dias após a colocação do implante. Após nove dias, os rufiões foram substituídos pelo reprodutor, tratado com 01 implante, com o qual as fêmeas permaneceram durante 51 dias, em sistema de monta a campo. 0 diagnóstico de gestação foi efetuado por ultra-sonografia e apresentou 36,7\%, $43,3 \%$ e $38,7 \%$ de animais gestantes no primeiro exame, e ao segundo, $36,7 \%, 46,7$ e $48,4 \%$ para os grupos $1 \mathrm{M}, 2 \mathrm{M}$ e $\mathrm{C}$, respectivamente. Não houve diferença significativa entre o intervalo efeito macho/cios férteis $(20,8 \pm 10,26 ; 25,0 \pm 12,75$ e $27,0 \pm 9,68$ dias $),$ encarneiramento/acasalamentos férteis $(11,8 \pm 10,26 ; 16,0 \pm 12,75$ e $18,0 \pm 9,68$ dias), taxa de fertilidade (43,3\%; 53,3\%; $51,6 \%$ ), taxa de parição $(36,7 \% ; 53,3 \%$ e $48,4 \%)$, prolificidade $(1,36 ; 1,50$ e 1,27$)$ entre os grupos $1 \mathrm{M}, 2 \mathrm{M}$ e C, respectivamente. A ocorrência de um efeito de facilitação social, provavelmente permitiu que fêmeas não tratadas (C) voltassem a ciclar. O tratamento com melatonina foi capaz de adiantar a estação reprodutiva, permitindo acasalamentos de primavera/verão e proporcionando parições de outono/inverno.

Palavras-chave: Hormônios. Ovinos. Estro animal. Fotoperiodismo. Pineal animal. 


\begin{abstract}
LOUREIRO, M. F. P. Oestrus induction with melatonin implant in Suffolk. [Indução do estro por implante de melatonina em ovinos da raça Suffolk]. 2003. $68 \mathrm{f}$. Dissertação (Mestrado em Medicina Veterinária) - Faculdade de Medicina Veterinária e Zootecnia, Universidade de São Paulo, São Paulo, 2003.
\end{abstract}

Ninety one Suffolk ewes were randomly allotted to none (control group), single (group $1 \mathrm{M}$ ) or two (group $2 \mathrm{M}$ ) melatonin slow releasing subcutaneous implants (18 mg, Mélovine) during spring season in the west region of São Paulo. Fourty two days after the implantation ewes were submitted to ram effect trough vasectomized teasers exposition and substituted by a ram treated with one melatonin implant following 51 days of mating period. Pregnancy diagnosis was performed by real-time ultrasound showing $38.7,36.7$ and $43.3 \%$ of pregnancy for groups $\mathrm{C}, 1 \mathrm{M}$ and $2 \mathrm{M}$ at the first examination, and $48.4,36.7$ and $46.7 \%$ of pregnancy respectively at the second examination. It was observed no significant difference between ram effect / fertile oestrus $(27.0 \pm 9.68,20.8 \pm 10.26,25.0 \pm 12.75$ days $)$, mating / pregnancy $(18.0 \pm 9.68,11.8 \pm 10.26,16.0 \pm 12.75$ days $)$, fertility rate $(51.6 \%, 43.3 \%, 53.3 \%)$ parturition $(48.4 \%, 36.7 \%, 53.3 \%)$, prolificity $(1.27,1.36,1.50)$ for groups $\mathrm{C}, 1 \mathrm{M}$ and $2 \mathrm{M}$ respectively. The occurrence of social facilitation effect probably permitted the untreated group (control group) returned to cycle. Melatonin treatment advanced the reproductive season permitting spring / summer mating and autumn / winter parturitions.

Key words: Hormones. Ovine. Animal oestrous. Photoperiod. Animal pineal. 


\section{LISTA DE FIGURAS}

Figura 1 - Representação do fotoperíodo no dia 21 de cada mês, na região de Valparaíso - SP.

Figura 2 - (A) Pistola específica para inserção do implante de melatonina e (B) local de administração

Figura 3 - Passos do processo de separação do plasma: (A) sangue total, (B) sangue centrifugado e (C) plasma aliquotado

Figura 4 - Distribuição do percentual de fêmeas gestantes nos diferentes grupos experimentais, em relação ao efeito macho (02 de dezembro) e encarneiramento (11 de dezembro) (1M - um implante; $2 \mathrm{M}$ - dois implantes; $\mathrm{C}$ - controle)

Figura 5 - Distribuição da percentagem de partos simples e gemelares, por grupo experimental ( $\mathrm{C}$ - controle; $1 \mathrm{M}$ - um implante; $2 \mathrm{M}$ - dois implantes) 


\section{LISTA DE TABELAS}

Tabela 1 - Distribuição do número de dias de chuva, precipitação pluviométrica em milímetros $(\mathrm{mm})$ e temperatura máxima e mínima absoluta - Valparaíso - SP - set 2000-ago 2001.

Tabela 2 - Distribuição dos pesos médios em $\mathrm{Kg}(X)$ e desvio padrão (s) das matrizes por grupo ( $1 \mathrm{M}$ - um implante, $2 \mathrm{M}$ - dois implantes, $\mathrm{C}-$ não tratado) no dia da colocação do implante subcutâneo de melatonina - Valparaiso - out 2000.

Tabela 3 - Representação esquemática do cronograma experimental

Tabela 4 - Resultados relativos a médias \pm desvio padrão (dias) do intervalo entre o efeito macho (EM) e cios férteis (CF), e do encarneiramento (REP) aos acasalamentos (AC), nos grupos experimentais ( $1 \mathrm{M}$ - um implante; $2 \mathrm{M}$ - dois implantes; $\mathrm{C}$ controle). Valparaíso (SP), dez 2000-jan 2001

Tabela 5 - Resultados relativos à taxa de gestação à primeira (1으) e segunda ( 2 OUS) ultra-sonografia, taxa de parição e fertilidade ao tratamento de indução do estro com melatonina. Valparaíso (SP), dez 2000-jun 2001 


\section{LISTA DE ABREVIATURAS E SIGLAS}

$\mu \mathrm{L} \quad$ microlitro

$1 \mathrm{M}$ grupo tratado com um implante de melatonina

$2 \mathrm{M}$ grupo tratado com dois implantes de melatonina

AANAT arilalkilamina $\mathrm{N}$-acetiltransferase

C grupo controle, não tratado

CL corpo lúteo

$\mathrm{E}_{2} \quad$ estradiol

eCG gonadotrofina coriônica eqüina

EDTA etilenodiamino tetracetato cálcico disódico

FSH hormônio folículo estimulante

g grama

HIOMT hidroxiindole-O-metiltransferase

$\mathrm{Kg}$ quilograma

L litro

LH hormônio luteinizante

$\mathrm{MHz}$ megahertz

$\mathrm{mL} \quad$ mililitro

$\mathrm{mm}$ milímetro

$\mathrm{P}_{4} \quad$ progesterona

$\mathrm{pg} / \mathrm{mL}$ pico grama por litro

$\mathrm{pmol} / \mathrm{L}$ picomol por litro

rapG receptor acoplador de proteina $G$

s desvio padrão da média

SAS Statistical Analysis System

$x \quad$ média 


\section{SUMÁRIO}

1 INTRODUÇÃO.

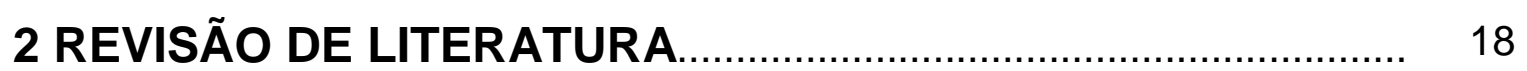

2.1 Glândula pineal e melatonina.............................................................. 19

2.2 Os ovinos e a estacionalidade reprodutiva............................................ 22

2.3 Métodos de indução do estro na contra estação reprodutiva.................... 23

2.3.1 Métodos clássicos........................................................................... 23

2.3.2 Método alternativo: melatonina exógena............................................. 25

3 MATERIAIS E MÉTODOS ............................................................ 36

3.1 Animais e manejo....................................................................... 38

3.2 Agrupamento e tratamento dos animais.............................................. 39

3.3 Efeito macho e acasalamentos............................................................ 41

3.4 Diagnóstico de gestação..................................................................... 41

3.5 Estratégia e colheitas de sangue ....................................................... 42

3.6 Análise estatística........................................................................ 43

3.7 Cronograma Experimental................................................................ 44

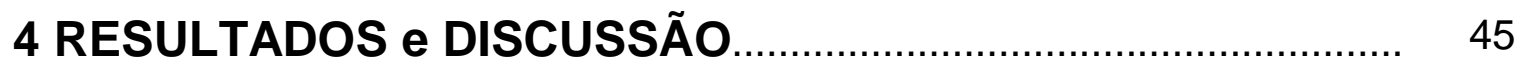

4.1 Resposta ao Efeito Macho e Acasalamentos............................................ 46

4.2 Gestação, Parição e Fertilidade ao tratamento de indução do estro com

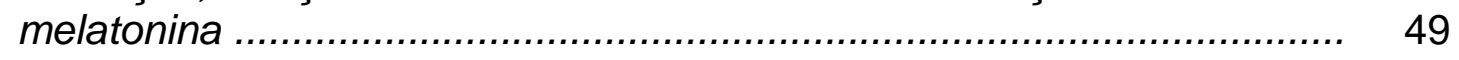

4.3 Prolificidade .............................................................................. 52

4.4 Proporção Sexual....................................................................... 54

4.5 Peso das crias ao nascimento e desmame .......................................... 54 
5 CONCLUSÃO

REFERÊNCIAS. 


\section{INTRODUÇÃO}

A procura por ovinos no Brasil é crescente, principalmente quando nos referimos a produção de carne, mais especificamente pela do cordeiro. O ovino tinha sua imagem diretamente ligada à produção de lã, porém essa associação sofreu uma mudança acentuada nos últimos anos, devido aos baixos preços praticados no mercado interno e externo. Grande parte dos criadores direcionou sua criação para atender a demanda crescente de carne ovina. Porém ainda os números são insatisfatórios para suprir a carência do mercado. Para atingir tal patamar, o sistema de produção precisar ser cíclico e regular.

Na região Sudeste do Brasil, os ciclos ovulatórios de ovinos especializados na produção de carne ocorrem do final do verão ao início do inverno, devido a poliestria estacional existente entre os pequenos ruminantes, onde o aumento do fotoperíodo leva à inibição de sua atividade reprodutiva. Esse fato faz com que a produção de carne concentre-se de novembro a fevereiro, resultando em um mercado também sazonal. Além do mais, a falta de organização da cadeia de produção, da padronização dos produtos e derivados, gera inconstância de oferta, prejudicando a manutenção do hábito de consumo desses produtos. Esta situação resulta na importação de carne ovina dos demais países do Cone Sul, cuja qualidade está, muitas vezes, aquém do desejável.

Tendo em vista esse quadro, a intensificação do manejo reprodutivo é uma saída estratégica para o aumento da produtividade do rebanho ovino. Desta forma, a quebra da estacionalidade reprodutiva por meio da indução do estro na primavera resultaria em parições de outono, possibilitando uniformizar a produção de carne e 
derivados de origem ovina, promovendo uma oferta constante de produtos, reprodutores e matrizes para rebanhos em formação.

A busca de uma alternativa, tal como um programa com baixos custos e facilidade de manejo, motivou a utilizar um hormônio que é de estrutura idêntica entre os vertebrados, a melatonina, que vem sendo eficaz na forma de implantes subcutâneos em animais de aptidão laneira na Oceania, porém nunca utilizada a campo no Brasil.

O implante inserido via subcutânea durante a primavera permitiria ao animal interpretar uma situação de ausência de luminosidade ambiente, desencadeando cios naturais em plena estação de anestro fisiológico. Além disso, promoveria incremento na produção espermática e na libido dos reprodutores.

Em países como a Austrália, a indução do estro em ovelhas da raça Merino vem sendo realizada desde a década de 90 com o uso de implantes de melatonina, que de forma prática permite o reinício da atividade cíclica na primavera, possibilitando que gestações ocorram em períodos de maior e melhor disponibilidade de alimento (STAPLES et al., 1992; WILLIAMS et al., 1992).

Pela falta de informação sobre a utilização desses implantes no Brasil foi desenvolvido o presente trabalho, que teve como objetivos verificar a quebra da estacionalidade na contra estação reprodutiva, e o efeito de diferentes doses de melatonina exógena, analisando as variáveis: intervalo entre efeito macho e cios férteis, intervalo entre o encarneiramento e acasalamentos férteis, sincronização do estro, taxa de gestação medida ao primeiro e segundo exame ultra-sonográfico, taxa de fertilidade, taxa de parição, prolificidade, morte embrionária e fetal, e proporção sexual. A hipótese testada é de que a melatonina de forma dose dependente altera parâmetros reprodutivos em fêmeas Suffolk no período de anestro estacional. 


\section{REVISÃO DA LITERATURA}

A glândula pineal é um tradutor neuroendócrino, à qual são atribuídas diversas funções, sendo a principal influenciada pelo fotoperíodo (TOSINI; FUKAHARA; 2003).

\subsection{Glândula pineal e melatonina}

A atividade da pineal influenciada pelo fotoperíodo é mediada pela substância N-acetil-5-methoxitriptamina ou melatonina, que tem função endócrina intimamente ligada ao sistema reprodutivo (KARSCH et al., 1984; LINCOLN; SHORT, 1980; REITER, 1991). A glândula pineal é altamente vascularizada e formada por dois tipos de células: os pinealócitos e as células neurogliais, sendo a melatonina uma indoleamina produzida pelos pinealócitos (BRZEZINSKI, 1997).

Um traço altamente conservado na fisiologia dos vertebrados é o ritmo diário na produção de melatonina, com os valores mais altos ocorrendo durante a noite (BITTMAN; DEMPSEY; KARSCH, 1983; KARSCH et al., 1984). Sua concentração plasmática é baixa durante o dia, com exceção aos animais que permanecem no escuro. A exposição à luz durante a noite causa um rápido declínio na concentração de melatonina circulante e na glândula pineal (ARENDT, 1995; BRZEZINSKI, 1997).

As mudanças nas concentrações de indoleaminas na pineal, entre o dia e a noite, são regidas por mudanças na atividade da arilalkilamina $\mathrm{N}$-acetiltransferase (AANAT), conhecida como enzima do ritmo de melatonina (GANGULY; COON; KLEIN, 2002) que aumenta durante a noite (KLEIN et al., 1997). A exposição de um 
animal à luz por 5 minutos durante a noite, diminui pela metade a atividade da AANAT e, por 10 minutos, causa sua inibição (TOSINI; FUKUHARA, 2003).

A melatonina, por sua vez, atua como um cronômetro fisiológico, onde o padrão de secreção noturna gera um sinal endócrino para determinar o comprimento do dia (ARENDT, 1995), uma vez que a mudança no nível de iluminação entre a noite e o dia oscila entre 0,1 a 100.000 lux (TOSINI; FUKUHARA, 2002). Dessa forma, o modelo de secreção de melatonina transmite informações relativas ao "ciclo luz-escuro" para a regulação fisiológica do corpo, em relação a sazonalidade e ciclo circadiano (ARENDT, 1995).

Recentemente, Gómez Brunet et al. (2002) demonstraram que uma maior secreção de melatonina em ovinos está ligada diretamente à hiperplasia da glândula pineal, que ocorre em alguns indivíduos de uma mesma raça, devido a um maior número de pinealócitos. Estudos em andamento, dos mesmos autores, visam identificar o gene que determina o peso da glândula pineal.

Informações relacionadas com a luminosidade, captadas pela retina, são transformadas em impulsos nervosos e transmitidos por via longa, através da medula, ao gânglio cervical superior, e desse à pineal (MALPAUX et al., 1996). Durante as horas de luz, células fotoreceptoras na retina são hiperpolarizadas, o que inibe a liberação de norepinefrina; o sistema retino-hipotálamo-pineal está quiescente e pouca melatonina é secretada. No final do dia, bem como no escuro, os fotoreceptores, despolarizados, liberam norepinefrina, a qual ativa os pinealócitos que contém os receptores adrenérgicos $\alpha 1$ e $\beta 1$. A ligação da norepinefrina aos receptores gera um aumento intracelular de AMPc nos pineaócitos, culminando na elevação da produção da AANAT, que regula a taxa de síntese, e inicia a produção e liberação de melatonina (BRZEZINSKI, 1997; WITT-ENDERBY; LI, 2000). A ação 
fisiológica desse hormônio depende da expressão do receptor acoplador de proteína $G$ (rapG). Dois tipos de rapG são conhecidos, um de alta afinidade denominado $M_{1}$ e outro de baixa afinidade, o $\mathrm{MT}_{2}$. $\mathrm{O}$ primeiro parece ser o subtipo funcionalmente importante, particularmente nos casos de sazonalidade (HAZLERIGG, 2001) e é expresso no cérebro, na pars tuberalis e nos tecidos periféricos, além da retina (BARRET et al., 2003). A retina em várias espécies de vertebrados também sintetiza melatonina, porém o papel dessa síntese ainda não está elucidado (TOSINI; FUKUHARA. 2003).

A melatonina é sintetizada a partir do triptofano, um aminoácido essencial obtido através da dieta, que sofre uma hidroxilação e uma descarboxilação até ser convertido em serotonina, presente em altas concentrações na pineal (HARUMl; MATSUSHIMA, 2000; SELMAOUI; OGUINE; THIBAULT, 2001). A conversão de serotonina em melatonina envolve uma acetilação e uma metilação, feitas pela AANAT e pela hidroxiindole-O-metiltransferase (HIOMT). Com o aumento de sua síntese, a melatonina entra na corrente sanguínea através de difusão passiva (BRZEZINSKI, 1997). Dessa forma, esse hormônio pode ser mensurado no sangue e no fluido cérebroespinhal e seus receptores estão localizados dentro e fora da barreira hematencefálica. Acredita-se que os receptores de melatonina ligados a reprodução estejam localizados no hipotálamo-médio-basal (O'CALLAGHAN et al., 1999; TRICOIRE et al, 2002).

Quando administrada pela via endovenosa, a melatonina é rapidamente distribuída e eliminada, com uma meia vida sérica de 0,5 a 5,6 minutos. Sua metabolização por hidroxilação ocorre principalmente no fígado, gerando o metabólito 6-hidroximelatonina, que se conjuga com o ácido sulfúrico ou glucurônico 
e é excretada na urina como 6-sulfatoximelatonina, seu principal metabólito (BRZEZINSKI, 1997).

\subsection{Os ovinos e a estacionalidade reprodutiva}

A espécie ovina é poliéstrica sazonal, sendo que o principal regulador da atividade reprodutiva é a alteração do comprimento dos dias ao longo do ano (MALPAUX et al., 1996; THIÉRY et al., 2002). Os animais dessa espécie são chamados de "animais de dias curtos", por apresentarem manifestações estrais do final do verão ao início do inverno, onde a quantidade de horas de luz diária sofre um decréscimo (CHEMINEAU et al., 1992; NOËL et al., 1999; MALPAUX et al., 1988).

Por ser o fotoperíodo um evento terrestre estável e a duração do dia estar intimamente ligada à disponibilidade de alimento em cada estação do ano, os herbívoros estritos desenvolveram um ritmo reprodutivo relacionado a esse fator (BRONSON, 1988). Assim, a sazonalidade reprodutiva foi a forma encontrada pela natureza para a perpetuação de determinadas espécies, tal como os ovinos e caprinos, onde a primavera é o tempo ideal para parição (THIÉRY et al., 2002), contando com a abundância de alimentos e temperatura amena, garantindo assim maior sobrevivência das crias (WILLIAMS; HELLIWELL, 1993).

Nas espécies bovina e suína, a expressão fisiológica da sazonalidade foi atenuada ou suprimida, porém na maioria das raças de ovinos, caprinos e eqüinos, originalmente oriundos de latitude com clima temperado, ela foi mantida (MALPAUX et al., 1997; THIÉRY et al., 2002; ZAIEM et al., 2000). 
Um dos fatores que rege o grau de estacionalidade das diferentes raças de pequenos ruminantes é o componente genético (WILLIAMS; HELLIWELL, 1993). Tal fato foi evidenciado por Gómez Brunet et al. (2002) em relação ao peso da pineal e o número de pinealócitos de cordeiros que, desde a primeira semana de vida, demonstraram diferenças genéticas previamente observadas em indivíduos adultos.

Nos dois sexos existe um período de atividade sexual máxima que se estende, no Hemisfério Norte, de agosto a janeiro (do verão ao início do inverno), com seu auge no outono. A atividade sexual mínima, de fevereiro a julho (inverno e primavera) se caracteriza, na fêmea, pelo anestro estacional e, no macho, pela diminuição da libido e da produção espermática, em quantidade e qualidade (THIMONIER, 1996). Tal fato se reflete diretamente na cadeia de produção de carne ovina, diminuindo a eficiência reprodutiva das fêmeas, ao longo de sua vida reprodutiva (WHEATON; POHL; WINDELS, 1990).

\subsection{Métodos de indução do estro na contra estação reprodutiva}

Com as limitações impostas pela sazonalidade reprodutiva, houve a necessidade de desenvolver uma estratégia de tratamento que permitisse a flexibilização e controle dos períodos de acasalamento e nascimento (HARESIGN, 1992a).

\subsubsection{Métodos clássicos}

A flexibilização ocorreu através de mudanças fotoperiódicas que foram usadas para manipular o comprimento do dia, considerando o fotoperíodo como o 
temporizador dos eventos reprodutivos (CHEMINEAU et al. 1992; ARENDT, 1995). Entretanto, tais tratamentos se mostraram inviáveis em rebanhos ovinos criados extensivamente (STAPLES et al., 1992).

A utilização do "efeito macho" no final da contra estação reprodutiva, favorece e antecipa o início da atividade cíclica ovariana. O macho libera uma substância volátil, o feromônio, que causa nas fêmeas um rápido aumento na concentração plasmática do hormônio luteinizante (LH) (REKIK; BRYANT; CUNNINGHAN, 1991; REKWOT et al., 2001) e provoca uma estimulação quase que imediata da atividade ovariana (OLDHAM; MARTIN, 1978; OLDHAM; MARTIN; KNIGHT, 1978; PERKINS; FITZGERALD, 1994); porém, a manifestação do primeiro estro sob esse estímulo pode não ser acompanhada de ovulação (OLDHAM; MARTIN; KNIGHT, 1978; ROJERO et al., 2001). Quando esta ocorre, forma-se na maioria das ovelhas $(61,1 \%)$ um corpo lúteo $(C L)$ de curta duração e um novo ciclo tem início aproximadamente após sete dias e, neste, a meia vida do CL pode ter duração normal (KNIGHT; TERVIT; FAIRCLOUGH, 1981). Em adição, pelo fato de se encontrarem em anestro estacional no momento do efeito macho, a produção de progesterona decorrente da primeira ovulação não é suficiente para desencadear manifestação de comportamento de estro, mas seria suficiente para desencadear novos ciclos ovulatórios normais, tanto na duração do CL, quanto do comportamento estral (OLDHAM; MARTIN, 1978).

Em regiões próximas ao Equador, o efeito macho mostra-se mais eficaz em animais oriundos de climas temperado e subtropical do que em animais de clima tropical, uma vez que estes apresentam baixa estacionalidade (CARLES; KIPNGENO, 1986). 
Com sucesso, é possível conseguir a quebra da estacionalidade reprodutiva com a associação de progestágenos e gonadotrofina coriônica eqüina (eCG). Porém seu uso em rebanhos ovinos extensivos torna-se restrito, pelo manejo requerido, e pela manifestação de um único cio, seguido de anestro, caso o animal não se torne gestante (STELLFLUG et al., 1994). Em nosso país, a grande extensão territorial não nos permite indicar um mesmo tratamento, no mesmo período do ano ou usando uma mesma dose de eCG, pois as diferentes raças e condições de manejo, associadas à latitude onde são criadas, exigem protocolos diferentes. A dose de eCG recomendada em países do Hemisfério Norte é excessiva para nossos rebanhos carniceiros, e seu uso indevido resulta em superovulação e aumento exagerado no números de fetos, o que acarreta perdas por toxemia da gestação, com morte da mãe e crias (TRALDI, 2001).

\subsubsection{Método alternativo: melatonina exógena}

Através da descoberta da relação hipotálamo-pineal, tornou-se possível "diminuir o comprimento do dia" farmacologicamente (STAPLES, 1992). Em pesquisas pioneiras com ovinos, Nett e Niswender (1982) confirmaram que o tratamento com melatonina exógena é capaz de reproduzir, de forma artificial, o escotoperíodo. Prosseguindo nessa linha de pesquisa, diversos grupos observaram uma clara recrudescência da atividade sexual nos animais tratados, e igualmente reconheceram o potencial desse hormônio na antecipação da estação reprodutiva (ARENDT et al., 1983; BITTMAN; DEMPSEY; KARSCH, 1983; KENNAWAY; GILMORE; SEAMARK, 1982; ENGLISH et al., 1986; KARSCH et al., 1984; KENNAWAY; DUNSTAN; STAPLES, 1987; POULTON et al., 1986), e no 
desempenho reprodutivo (DUROTOYE et al., 1991; KOUIMTZIS; BELIBASAKI; DONEY, 1989; SHARON; FORSYTH; ARENDT, 1992; STELLFLUG; FITZGERALD; PARKER, 1989).

Entretanto, trabalhos experimentais iniciados na década de 80 em latitude $38^{\circ}$ Sul, com ovinos de diferentes graus de estacionalidade (Romney Marsh, Border Leicester x Merino e Merino), demonstraram que a atividade ovariana induzida pelo uso de melatonina é mais curta, comparativamente à estação de reprodutiva natural (CHEMINEAU et al., 1992; WILLIAMS et al., 1992).

Dentre as diferentes vias de administração desse hormônio, são citadas: injeções intramusculares (NETT; NISWENDER, 1982; NOËL et al., 1999), adição na alimentação (ARENDT et al., 1983; WHEATON; POHL; WINDELS, 1990), implantes intra-ruminais (bolus) (POULTON et al., 1987), doses orais (ROBINSON et al., 1991; 1992; WIGZELL et al., 1990), implantes vaginais (RODWAY et al., 1990), infusões (ROBINSON et al., 1992) e implantes subcutâneos (DUROTOYE et al., 1991; FORCADA et al., 2002; GÓMEZ BRUNET et al., 1995; HARESIGN, 1992a, 1992b; LALIOTIS et al., 1998; REKIK; BRYANT; CUNNINGHAN, 1991; RONDON et al., 1996; STELLFLUG et al., 1994; STELLFLUG; FITZGERALD; PARKER, 1989; SWEENEY; O'CALLAGHAN, 1996; WILLIAMS et al., 1992). Apesar do interesse comercial ser de longa data (ARENDT et al., 1983; KENNAWAY; GILMORE; SEAMARK, 1982), e do sucesso obtido pelas técnicas desenvolvidas e testadas experimentalmente, algumas se mostraram impraticáveis quando utilizadas em um grande número de animais (DUROTOYE et al., 1991).

A solução para o uso a campo foi encontrada pelo pesquisador Linton Staples, que desenvolveu o implante subcutâneo de liberação lenta. Este foi inicialmente testado em ovelhas da raça Merino, na Austrália, e posteriormente em 
ovelhas Suffolk e Mule (Bluefaced Leicester x Swaledale), no Reino Unido. O implante foi patenteado em $1987^{1}$ e posteriormente comercializado, por sua praticidade e eficácia, recebendo o nome de Regulin $^{\circledR}$ ou Melovine ${ }^{\circledR}$. De formato cilíndrico, possui um núcleo com 18 mg de melatonina, no interior de uma matriz formada por condensadores e lubrificantes, que mede $2 \mathrm{~mm}$ de diâmetro e $4 \mathrm{~mm}$ de comprimento (HARESIGN; PETERS; STAPLES, 1990; WHEATON; POHL; WINDELS, 1990). Esse núcleo, biodegradável (HARESIGN, 1992a), é recoberto por uma fina camada de polímeros que permitem uma difusão limitada do hormônio através dessa barreira, de aproximadamente $250 \mu \mathrm{g} / \mathrm{dia}^{-1}$ (WILLIAMS et al., 1992). A aplicação é efetuada no tecido subcutâneo com o auxílio de uma pistola, próxima a base da orelha, sendo sua remoção efetuada apenas cirurgicamente (STAPLES et al., 1992; WHEATON; POHL; WINDELS, 1990).

Um único implante administrado em uma fêmea ovina pesando entre 40-60 Kg mostrou que a concentração plasmática deste hormônio, mensurada durante o dia na veia jugular contralateral ao implante, permanece elevada (300-900pmol/L $\mathrm{L}^{-1}$ ) por um período de aproximadamente 70 dias, mimetizando os valores fisiológicos noturnos, de 300 a 1000pmol/L ${ }^{-1}$ (STAPLES et al., 1992; WILLIAMS et al., 1992). Em ovelhas adultas da raça Rasa Aragonesa que receberam implante subcutâneo, Forcada, Zúñiga e Abecia (2002) registraram valores médios de $341 \pm 39 \mathrm{pmol} / \mathrm{L}^{-1}$ durante as horas de luz e $553 \pm 45 \mathrm{pmol} / \mathrm{L}^{-1}$ durante as horas de escuro. Essa elevada concentração de melatonina circulante durante todo o dia permite que, mesmo em condições de fotoperíodo longo de primavera, os animais interpretem e respondam de forma semelhante àquela dos dias curtos, com estímulo e retorno à ciclicidade estral (O'CALLAGHAN et al., 1991).

\footnotetext{
${ }^{1}$ European Patent Organization Number 246910
} 
Nos diversos estudos efetuados em rebanhos da Austrália e Nova Zelândia, Williams et al. (1992) utilizaram um único implante de melatonina, sendo a justificativa para tanto, o peso das fêmeas adultas das raças laneiras que variavam entre 40 e $60 \mathrm{Kg}$. Em animais mais pesados (acima de $70 \mathrm{Kg}$ ) do Reino Unido, o emprego de dois implantes pelos mesmos autores revelou uma tendência em ser mais eficaz. Porém, tal tendência já havia sido demonstrada por Haresign, Peters e Staples (1990) utilizando animais puros e cruzados da raça Suffolk, com a aplicação de dois implantes.

No hipotálamo, os efeitos do implante podem ser observados após 40 dias. A presença desse hormônio 24 horas na circulação, aumenta a secreção pulsátil de GnRH e provoca a secreção cíclica do hormônio folículo estimulante (FSH) e do LH, permitindo o desencadeamento da atividade estral em plena estação de anestro fisiológico da espécie. Além disso, no macho, há o retorno da libido e incremento na produção espermática, viabilizando o uso da monta natural e aumentando as possibilidades de sucesso do programa (CHEMINEAU et al., 1996).

Para utilização do método, com a finalidade de induzir resposta ovariana em ovelhas em anestro fisiológico, alguns preceitos devem ser adotados, uma vez que a época de inserção do implante é de suma importância para o sucesso do tratamento. Dessa forma, Williams et al. (1992) provaram que o método é eficaz em animais cruza Merino, quando o implante é colocado do início da primavera ao início do verão, e ineficaz quando as fêmeas são tratadas na metade do outono, período de declínio natural do comprimento do dia. De modo geral, recomenda-se a utilização do tratamento pelo menos 60 dias antes da estação reprodutiva (HARESIGN; PETERS; STAPLES, 1990). 
Fatores como estacionalidade da raça, situação geográfica, clima e época do ano também deverão ser levados em consideração, quando da escolha do melhor momento para o início do tratamento. Outro fator importante a ser considerado são os machos jovens e adultos do rebanho, que devem ser obrigatoriamente separados das fêmeas antes do início do tratamento (GÓMEZ BRUNET et al., 1995), ou seja, desde o início da primavera (HARESIGN; PETERS; STAPLES, 1990).

Williams et al. (1992) estudando diversas raças em diferentes países demonstraram que o tratamento com melatonina é igualmente eficaz na indução do estro em raças que apresentam parâmetros de estacionalidade reprodutiva extremos, como a Romney Marsh e a Suffolk, fortemente estacionais, e a Merino, a menos estacional das raças de lã fina. O mesmo fato foi observado por Staples et al. (1992) na Austrália com fêmeas Corriedale, Romney Marsh e Merino. Porém este autor concluiu que, para o tratamento ser eficaz, o período de refratariedade reprodutiva de primavera deve ser considerado e sugeriu a hipótese que raças menos estacionais desenvolveriam um estado de receptividade aos dias curtos mais cedo que as raças mais estacionais. Desse modo, Merino e cruzas Merino foram receptivas ao tratamento com melatonina na primavera e verão, enquanto a Romney Marsh tornou-se receptiva somente no final do verão/início do outono. Essa situação ficou evidenciada no experimento acima citado (WILLIAMS et al. 1992), onde grupos experimentais das raças Romney Marsh e Suffolk necessitaram de um segundo implante de $18 \mathrm{mg}$ para responderem positivamente ao tratamento, diferentemente da Merino, o que denota a variação da resposta das diferentes raças devido a maior ou menor refratariedade sexual aos dias longos.

O efeito macho é indispensável para que a estratégia de ação do tratamento com o uso de melatonina exógena seja efetivo (OLDHAM; MARTIN, 1978). Esse 
estímulo favorece a sincronia na manifestação dos estros e ovulações (HARESIGN, 1992a; STAPLES et al., 1992; SWEENEY; O'CALLAGHAN, 1996; WILLIAMS et al., 1992), e deve ser realizado de 35 a 40 dias após a colocação do implante (HARESIGN, 1992a; OLDHAM; MARTIN, 1978; STAPLES et al., 1992). No entanto, será muito mais eficiente se os reprodutores ou rufiões forem igualmente tratados (CHEMINEAU et al., 1996). No entanto, a preferência sexual é marcante em ovinos adultos, que acasalam uma mesma fêmea diversas vezes antes de mostrar interesse por outra fêmea em estro (PRICE; BORGWARDT; DALLY, 2001).

Em geral, a indução de estro com melatonina, associado ao efeito macho, permite que os primeiros cios férteis ocorram cerca de 15 dias após a introdução do macho no rebanho, favorecendo acasalamentos no final da primavera e parições de outono (GÓMEZ BRUNET et al., 1995). Dessa forma, as ovelhas atravessariam a gestação em período de abundância de pastagens, favorecendo ambos, mãe e cordeiro, quanto ao peso ao nascimento e produção de leite (CHEMINEAU et al., 1996).

Estudos evidenciaram que ovelhas em anestro, isoladas dos reprodutores, não são capazes de ovular, diferente das que sofreram o efeito macho, onde ocorre um incremento significativo na taxa de ovulação (ROSA; JUNIPER; BRYANT, 2000a). Esta associação também demonstrou melhores resultados quanto a sincronização da data de concepção e nascimentos, e aumento significativo na taxa de parição (HARESIGN, 1992a; WILLIAMS et al., 1992).

Diversos experimentos realizados com ovelhas mestiças Merino na Austrália e na Nova Zelândia, mostraram que as concepções ocorrem cerca de 20 a 28 dias após o efeito macho. Nesses países, o tratamento foi eficiente em ovelhas acasaladas entre o início de outubro e janeiro, obtendo-se uma melhora na 
performance reprodutiva decorrente da redução na proporção de animais nãogestantes, associada ao aumento na proporção de partos gemelares, que foi de $24 \%$ no grupo controle e $37,2 \%$ no grupo de animais tratados. A atividade ovariana teve início cerca de um mês mais cedo nos animais tratados em relação ao grupo controle (WILLIAMS et al., 1992). Da mesma forma, na Grécia, a atividade reprodutiva de ovelhas das raças Karagouniki e East Friesland tratadas com melatonina teve início, respectivamente, 17 e 23 dias mais cedo que o lote controle (KOUIMTZIS; BELIBASAKI; DONEY, 1989).

Nas condições de latitude, longitude, e clima do Reino Unido, o tempo ideal encontrado para a introdução do macho em experimentos conduzidos por Haresign (1992a; 1992b) com animais Mule foi de cinco a seis semanas pós implante. O mesmo autor recomendou o uso de um reprodutor para cada trinta fêmeas, com permanência mínima de seis semanas no lote.

$\mathrm{Na}$ Espanha, o intervalo médio entre o efeito macho e as parições, em fêmeas da raça Merino, foi de 166,2 dias, e tanto a fertilidade quanto a prolificidade foram significativamente aumentadas pelo uso de melatonina, sendo de $64,5 \%$ e 1,15 nas tratadas e 51,3\% e 1,03 nas não tratadas, respectivamente (GÓMEZ BRUNET et al., 1995).

Estudos evidenciaram que ovelhas em anestro, isoladas dos reprodutores, não são capazes de ovular, diferente das tratadas com melatonina submetidas ao efeito macho, que tiveram um incremento significativo na taxa de ovulação (ROSA; JUNIPER; BRYANT, 2000b). Esta associação também demonstrou melhores resultados quanto a sincronização da data de concepção e nascimentos, e aumento significativo na taxa de parição (HARESIGN, 1992a; WILLIAMS et al., 1992). 
Haresign (1992b) sugeriu a existência de um "efeito de facilitação" entre animais tratados com melatonina e naqueles animais não tratados mantidos em conjunto durante o período experimental e igualmente submetidos ao efeito macho, o que resultou em manifestação de estro e ovulações em fêmeas do grupo controle. No entanto, não ficou estabelecido pelo autor qual tipo de interação, "fêmea-fêmea" ou "fêmea-macho-fêmea", foi eficaz na estimulação da atividade estral das fêmeas não tratadas. Tal sugestão foi confirmada por Zarco et al. (1995), que notaram um aumento da atividade luteínica em ovelhas em anestro expostas a ovelhas submetidas a tratamento hormonal com progestágeno e efeito macho, resultando em uma sincronia no desencadeamento dos estros, sugerindo uma associação de efeito macho e efeito fêmea na sincronização da atividade reprodutiva no período de contra-estação sexual.

Wallace et al. (1988) mostraram que, em ovelhas tratadas com melatonina, há um aumento na concentração plasmática de $\mathrm{P}_{4}$ durante a fase luteínica do ciclo estral, o que complementa a sugestão de Gómez Brunet et al. (1995), de que a melhora na fecundidade dos animais tratados com melatonina poderia ser atribuída ao efeito luteotrópico desse hormônio. Em adição, a melatonina exerce um efeito significante em relação à taxa de ovulação, sendo esta confirmada pela maior incidência de partos duplos (DUROTOYE et al., 1991; GÓMEZ BRUNET et al., 1995; HARESIGN,1992b; RODWAY et al., 1990; WHEATON; POHL; WINDELS, 1990; WIGZELL et al., 1986; WIGZELL et al., 1990).

Contudo, ao contrário do tratamento por um período curto de tempo, a melatonina pode surtir um efeito adverso na taxa de ovulação, diminuindo-a significativamente se administrada por um longo período. Quando usada na Irlanda 
em animais da raça Scottish Blackface no meio da estação reprodutiva, com o intuito de estendê-la, mostrou-se ineficaz (JORDAN; HANRAHAN; ROCHE, 1990).

Em um estudo realizado na Grã-Bretanha com 2563 ovelhas, Haresign, Peters e Staples (1990), obtiveram uma prolificidade de 1,15 cordeiros por fêmea parida. Anos mais tarde, Forcada, Zarazaga e Abecia (1995) igualmente notaram um aumento nos parâmetros reprodutivos (fertilidade e prolificidade) de ovelhas tratadas com melatonina, gerando 0,36 cordeiros por fêmea a mais que as controle. Em 2002, tal resultado foi confirmado com a utilização de 15 raças na Espanha, em um total de 17.738 animais, onde o tratamento com um implante de melatonina elevou de 1,34 para 1,47 o número de cordeiros nascidos por fêmea parida (ABECIA; FORCADA; ZÚÑIGA, 2002).

Na Nova Zelândia, McMillan e Sealey (1989) obtiveram um acréscimo de $72 \%$ na fertilidade de ovelhas da raça Coopworth tratadas com melatonina contra $41 \%$ nos controle, além de um aumento de $40 \%$ na prolificidade. Fato semelhante foi observado por Williams et al. (1992), que encontraram na raça Merino um acréscimo de $17,8 \pm 2,6$ cordeiros e nas cruzas Merino 17,6 $\pm 1,3$, em cada 100 fêmeas expostas ao tratamento.

Altos índices também foram encontrados por Zaiem et al. (2000) em ovinos de raças pouco estacionais na Tunísia, com taxa de fertilidade de 95,7\% na raça Queue fine de l'Ouest e 92,8\% na Noire de Thibar, e uma taxa de prolificidade de $123,8 \%$ e $129,2 \%$, respectivamente, contra $109,5 \%$ e $109,6 \%$ nos lotes controle.

Na raça deslanada Pelibuey, do México, criada em região que apresenta uma temperatura média anual de $23,8^{\circ} \mathrm{C}$ e precipitação pluviométrica de $1980 \mathrm{~mm}$, de 23 fêmeas tratadas com melatonina e manejadas a pasto, sem suplementação nutricional, 11 (47,8\%) apresentaram cio e pariram, e 11 (52,3\%) das 21 fêmeas do 
grupo controle. Vale ressaltar que as ovelhas dessa raça são leves, e apresentavam peso médio de $30 \mathrm{Kg}$ no momento da inserção do implante (ROJERO et al., 2001).

Estudando cinco raças diferentes de ovinos na França, Chemineau et al. (1996) obtiveram uma diferença significativa na taxa de fertilidade no lote tratado (86\%) em relação ao lote controle (79\%). A prolificidade observada foi igualmente significativa, com 1,51 cordeiros por ovelha parida no lote tratado, contra 1,44 no lote controle.

Wigzell et al. (1986) sugeriram que, além de aumentar a taxa de ovulação, a melatonina poderia também melhorar a sobrevivência embrionária. Porém Haresign (1992b) relatou uma perda embrionária de 6,3\% em ovelhas da raça Mule tratadas no final da primavera. Kaulfuss et al. (1997) testaram a acurácia do exame ultra-sonográfico no diagnóstico de perda embrionária precoce, comparando animais abatidos com os examinados in vivo, e concluiram que não há diferença significativa entre os métodos.

A melatonina pode ser também considerada uma alternativa para fotoestimulação no preparo de bodes e carneiros que acasalarão na contra estação reprodutiva (HANIF; WILLIAMS, 1991). Reprodutores ovinos que receberam o implante durante a contra estação reprodutiva e foram submetidos a colheita e congelamento de sêmen, revelaram uma melhora na competência dos espermatozóides, evidenciada pela alta viabilidade e elevada taxa de acrossomas intactos nas amostras criopreservadas (KAYA et al., 2001) e incremento na libido (HANIF; WILLIAMS, 1991).

Rosa; Juniper; Bryant (2000b) mostraram que a concentração média de melatonina em machos ovinos tratados $\left(649,7 \pm 281,4 \mathrm{pgmL}^{-1}\right)$ foi mais alta que nos animais não tratados $\left(18,3 \pm 2,4 \mathrm{pgmL}^{-1}\right)$. Quando comparados os valores da 
secreção de testosterona, novamente encontraram um incremento na concentração de aproximadamente 2,5 vezes para os tratados $\left(10,09 \pm 1,10 \mathrm{ngmL}^{-1}\right)$, em comparação ao controle $\left(4,28 \pm 1,88 \mathrm{ngmL}^{-1}\right)$.

Estudo do perfil hormonal da concentração plasmática de melatonina realizado por Rodrigues (2001) demonstrou que ovelhas lanadas das raças Suffolk e Romney Marsh possuem estacionalidade reprodutiva na região Sudeste do Brasil sendo, portanto indicadas no estudo e avaliação da possibilidade de indução do estro com implantes de melatonina em nosso país. 


\section{MATERIAIS E MÉTODOS}

O experimento foi realizado entre 01 de setembro de 2000 e 18 de agosto de 2001 na "Cabanha Araçá", zona rural da cidade de Valparaíso, Estado de São Paulo, localizada geograficamente na latitude de 21013'40"sul, longitude de 5052'06" oeste e altitude de 449 metros. O clima do município caracteriza-se por tropical/temperado. A precipitação pluviométrica, o número de dias de chuva e a temperatura mensal máxima e mínima estão representados na tabela 1.

Tabela 1 - Distribuição do número de dias de chuva, precipitação pluviométrica em milímetros (mm) e temperatura máxima e mínima absoluta - Valparaíso - SP - set 2000-ago 2001

\begin{tabular}{cccc}
\hline Meses & $\begin{array}{c}\text { Temperatura } \\
\text { Máxima } \\
\text { Absoluta }\left({ }^{\circ} \mathbf{C}\right)\end{array}$ & $\begin{array}{c}\text { Temperatura } \\
\text { Mínima } \\
\text { Absoluta }\left({ }^{\circ} \mathbf{C}\right)\end{array}$ & $\begin{array}{c}\text { Precipitação } \\
(\mathbf{m m})\end{array}$ \\
\hline Set & 35 & 11 & 124 \\
Out & 40 & 16 & 32 \\
Nov & 38 & 17 & 179 \\
Dez & 38 & 15 & 226 \\
Jan & 37 & 20 & 225 \\
Fev & 36 & 20 & 184 \\
Mar & 37 & 18 & 199 \\
Abr & 36 & 16 & 103 \\
Maio & 35 & 6 & 66 \\
Jun & 32 & 2 & 24 \\
Jul & 35 & 5 & 40 \\
Ago & 34 & 13 & 29 \\
TOTAL & - & - & 1431 \\
\hline
\end{tabular}

Fonte dos dados brutos: Valparaíso (SP). Instituto Agronômico - CIIAGRO, set 2000ago 2001 
Devido a localização geográfica, o solstício de verão (fotoperíodo máximo) em 21 de dezembro é de 13 horas e 17 minutos, e o solstício de inverno (fotoperíodo mínimo) em 23 de junho de 10 horas e 47 minutos, representando uma diferença de duas horas e trinta minutos. A figura 1 apresenta o número de horas de luz no dia 21 de cada mês, na região de Valparaíso.

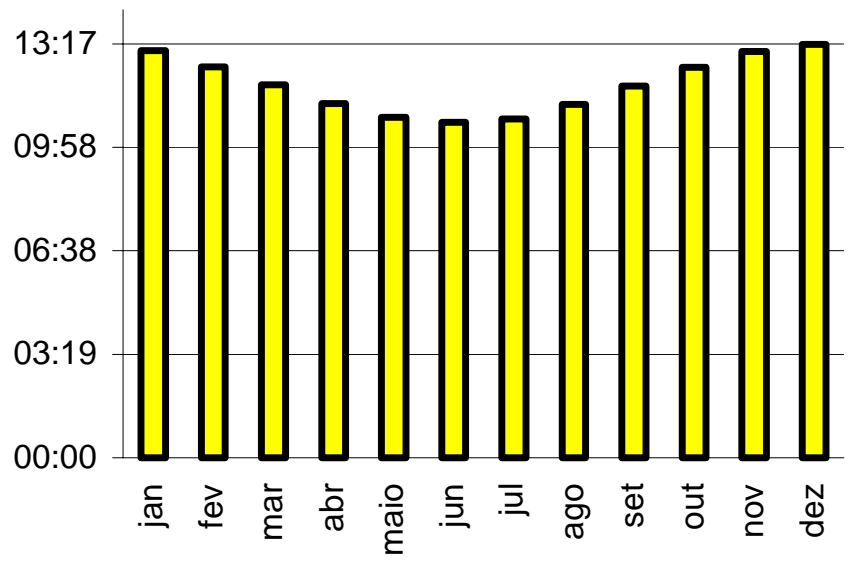

Fonte dos dados brutos: Araçatuba (SP).TMA - 63-1.

Figura 1 - Representação do fotoperíodo no dia 21 de cada mês, na região de Valparaíso - SP

\subsection{Animais e manejo}

Em 01 de setembro de 2000 (D. -92), noventa e uma fêmeas ovinas da raça Suffolk, um reprodutor da mesma raça e quatro rufiões sem raça definida, foram selecionados no plantel da cabanha. Dessas fêmeas, oitenta e cinco haviam parido na última estação reprodutiva e seis borregas apresentavam desenvolvimento corporal compatível com os parâmetros zootécnicos para o primeiro acasalamento (peso e estado corporal). 
Durante 50 dias as 91 fêmeas experimentais formaram um lote único e foram mantidas afastadas dos machos, com a finalidade de evitar qualquer contato visual, olfativo, tátil e audível. Precedendo o experimento, foram vermifugadas, tosquiadas, e casqueadas.

Os animais foram mantidos em sistema extensivo, em piquetes rotacionados de cost-cross (Cynodon sp) e capim estrela (Cynodon sp), em um total de dez hectares, e suplementados com sal mineral específico para ovinos. No terço final de gestação, as fêmeas foram suplementadas com 300 a 400g/animal/dia de concentrado, até o período de desmame.

Os cordeiros foram identificados e pesados ao nascimento e permaneceram a pasto com suas mães, suplementados em sistema de "creep feeding", até o momento do desmame, aos 60 dias de idade, quando foram novamente pesados, vacinados e vermifugados.

\subsection{Agrupamento e tratamento dos animais}

Após 50 dias (D. -42) do isolamento dos machos, as fêmeas experimentais foram pesadas (Tabela 2), identificadas e separadas em três grupos homogêneos, cada qual com duas borregas.

A distinção entre os grupos $1 \mathrm{M}, 2 \mathrm{M}$ e $\mathrm{C}$ se deu quanto ao tratamento de indução do estro: grupo $1 \mathrm{M}(\mathrm{n}=30)$, que recebeu um implante subcutâneo de $18 \mathrm{mg}$ de melatonina (Mélovine) ${ }^{1} ; 2 \mathrm{M}(\mathrm{n}=30)$ que recebeu 2 implantes e um terceiro grupo controle $(n=31)$, não tratado $(C)$. Dentre os machos, apenas o reprodutor recebeu um implante e tanto este, quanto os rufiões, permaneceram isolados das fêmeas.

\footnotetext{
${ }^{1}$ Mélovine - CEVA SANTÉ ANIMALE, La Ballastière, Libourne Cedex, França.
} 
Tabela 2 - Distribuição dos pesos médios em Kg (X) e desvio padrão (s) das matrizes por grupo (1M - um implante, $2 \mathrm{M}$ - dois implantes, $\mathrm{C}$ - não tratado) no dia da colocação do implante subcutâneo de melatonina - Valparaiso - out 2000

\begin{tabular}{cc}
\hline GRUPOS & $\begin{array}{c}\text { PESOS } \\
(\mathbf{X} \pm \mathbf{s})\end{array}$ \\
\hline $1 M(n=30)$ & $69,2 \pm 9,2$ \\
$2 M(n=30)$ & $68,0 \pm 7,1$ \\
$C(n=31)$ & $65,8 \pm 8,3$ \\
\hline
\end{tabular}

A inserção dos implantes foi efetuada segundo recomendação do fabricante (CEVA SANTÉ ANIMALE), no tecido subcutâneo próximo a base da orelha, utilizando uma pistola específica (Figura 2A). Para padronizar a administração, todos os implantes foram inseridos na base da orelha esquerda e as agulhas desinfetadas com solução a 10\% de álcool iodado, entre cada aplicação.

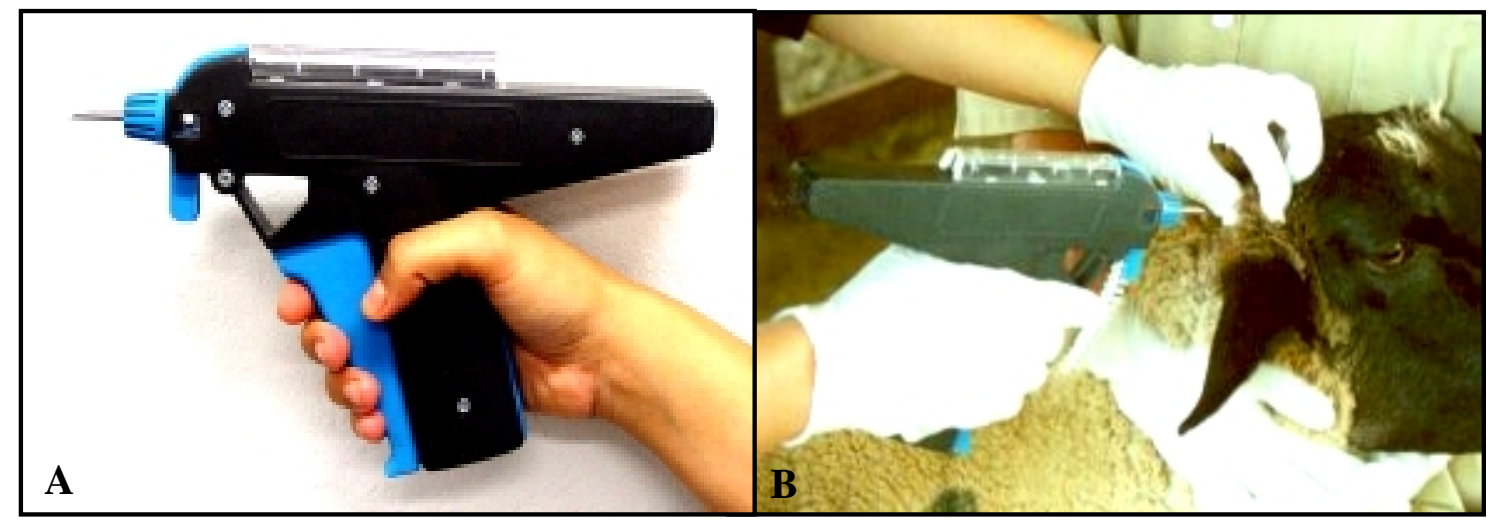

Figura 2 - (A) Pistola específica para inserção do implante de melatonina e (B) local de administração

Concomitante à inserção dos implantes, cada fêmea foi marcada na garupa com tinta óleo verde (grupo 1M), vermelha (grupo 2M) ou amarela (grupo C), visando facilitar a identificação dos animais e seus respectivos grupos, nos diferentes momentos do experimento. Finalmente, voltaram a formar um lote único a campo, onde permaneceram até o desmame. 


\subsection{Efeito macho e acasalamentos}

Passados 42 dias do início do tratamento, quatro rufiões foram introduzidos no lote a campo para realização do "efeito macho", uma vez que, segundo a literatura, os primeiros estros são inférteis. Esse momento foi considerado "D. zero" (D.0). Após nove dias (D.9) os rufiões foram substituídos pelo reprodutor, para que fossem efetuados os acasalamentos em sistema de monta a campo. Os animais permaneceram encarneirados durante 51 dias, sendo o reprodutor retirado do lote no D.60.

O intervalo entre o efeito macho e cios férteis foi determinado tomando como parâmetro a data do parto, da qual foi subtraído o tempo de gestação fisiológico da espécie ovina, equivalente a 148 dias (WHEATON; POHL; WINDELS, 1990; GÓMEZ BRUNET et al., 1995).

\subsection{Diagnóstico de gestação}

O diagnóstico de gestação foi realizado por ultra-sonografia em duas etapas, a primeira 44 dias após a introdução do reprodutor (D.53), e a segunda nove dias após a primeira avaliação (D.62), utilizando o aparelho VT 100 (Pie-Medical $\left.{ }^{\circledR}\right)^{2}$. Para o diagnóstico precoce, via transretal, foi utilizado transdutor linear de $6.0 \mathrm{MHz}$, que permite identificar a presença de pequenas vesículas $(5,0 \mathrm{~mm})$ com conteúdo anecóico nos cornos uterinos, indicativos de prenhez positiva, a partir dos 15 dias de gestação; após o $25^{\circ}$ dia, a vesícula embrionária apresenta diâmetro médio de 16,2 mm (LIMA, 2000), possibilitando maior acurácia dos resultados. Gestações

\footnotetext{
${ }^{2}$ Pie Medical ${ }^{\circledR}$, Nutricell - Nutrientes celulares, Campinas, SP. Brasil.
} 
superiores a 35 dias puderam ser diagnosticadas através da via transabdominal com transdutor convexo de $3.5 \mathrm{MHz}$. Em ambas abordagens foi utilizado carboximetilcelulose $^{3}$ como acoplador acústico e os animais foram mantidos em estação.

Para o parâmetro taxa de fertilidade, foi considerado a somatória de dados relativos aos animais gestantes no primeiro e segundo exames ultra-sonográficos e animais paridos.

\subsection{Estratégia e colheitas de sangue}

Para avaliação da resposta ao tratamento, foram colhidas amostras de sangue em tubos de $15 \mathrm{~mL}$ com $10 \mu \mathrm{L}$ de EDTA ,centrifugadas a 2.500 RPM por 15 minutos. O plasma foi aliquotado em duplicata em microtubos de $1.5 \mathrm{~mL}$, identificados e estocados a $-20 \stackrel{\circ}{C}$ (Figura 3).
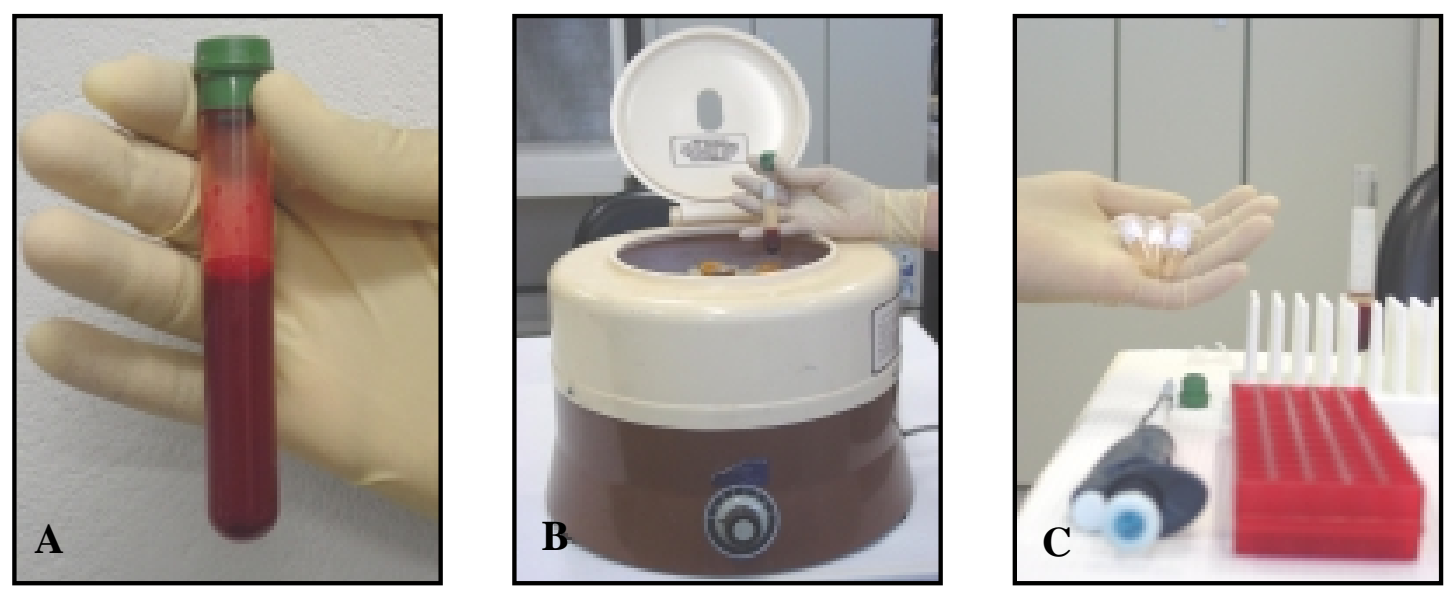

Figura 3 - Passos do processo de separação do plasma: (A) sangue total, (B) sangue centrifugado e (C) plasma aliquotado

\footnotetext{
${ }^{3}$ Carboximetilcelulose - CMC - Henrifarma Produtos Químicos e Farmaceuticos Ltda., São Paulo, SP., Brasil.
} 
A primeira amostra foi colhida no dia da colocação do implante e separação dos grupos experimentais (D.-42), para dosagem de progesterona $\left(P_{4}\right)$, visando a avaliação do estado de anestro fisiológico. A segunda colheita foi seriada e antecedeu setenta e duas horas à entrada dos rufiões (D.0), com intervalo de vinte e quatro horas, em um total de três colheitas, para posterior avaliação da concentração plasmática de estradiol $\left(E_{2}\right)$ e $P_{4}$. No momento do diagnóstico de gestação (D.53 e D.62), nova colheita foi efetuada exclusivamente nos animais que não apresentavam imagem ultra-sonográfica compatível com gestação, visando dosagem de $\mathrm{P}_{4}$, para avaliação de seu estado fisiológico.

Apesar das estratégias adotadas para a colheita de plasma, houve um incidente que levou ao descongelamento das amostras obtidas, impossibilitando que as dosagens de $\mathrm{P}_{4}$ e $\mathrm{E}_{2}$ fossem efetuadas.

\subsection{Análise estatística}

O delineamento experimental foi inteiramente casualizado, considerando-se cada fêmea como uma unidade experimental.

As características avaliadas foram: intervalo entre efeito macho e cios férteis, intervalo entre o encarneiramento e acasalamentos férteis, sincronização do estro, taxa de gestação medida ao primeiro e segundo exame ultra-sonográfico, taxa de fertilidade, taxa de parição, prolificidade, morte embrionária e fetal, e proporção sexual.

Para avaliação de taxas foi utilizado o Teste de $\chi^{2}$; a prolificidade e as demais variáveis foram submetidas a análise de variância pelo teste $F$ (PROC GLM), 
pelo sistema computacional Statistical Analysis System (SAS, 1985) com nível de significância de $5 \%(p<0,05)$.

\subsection{Cronograma Experimental}

A tabela 3 apresenta o cronograma experimental, que se estendeu durante 352 dias.

Tabela 3 - Representação esquemática do cronograma experimental

\begin{tabular}{|c|c|c|c|}
\hline Dia & Data & Evento - fotoperíodo (horas luz ) & $\begin{array}{l}\text { Colheitas } \\
\text { de sangue }\end{array}$ \\
\hline D. -92 & $01 / 09 / 2000$ & Separação entre machos e fêmeas - 11h 34' & ------ \\
\hline D. -42 & $21 / 10 / 2000$ & $\begin{array}{l}\text { Separação dos lotes, inserção dos implantes de melatonina }-12 \mathrm{~h} \\
33^{\prime} \\
\text { Temperatura ambiente: } 40^{\circ} \mathrm{C}\end{array}$ & Total \\
\hline D. 0 & $02 / 12 / 2000$ & Início do efeito macho (entrada dos rufiões) - 13h 11' & Seriada \\
\hline D.9 & $11 / 12 / 2000$ & $\begin{array}{l}\text { Encarneiramento - Início dos acasalamentos } \\
\text { (troca dos rufiões pelo reprodutor) - } 13 \mathrm{~h} 15^{\prime}\end{array}$ & ----- \\
\hline D.53 & $24 / 01 / 2001$ & $\begin{array}{l}1^{\mathrm{a}} \text { ultra-sonografia } \\
\text { (44 dias pós encarneiramento) }-13 \mathrm{~h} 05^{\prime}\end{array}$ & Parcial \\
\hline D.60 & $31 / 01 / 2001$ & $\begin{array}{l}\text { Retirada do reprodutor } \\
\text { (fim dos acasalamentos) - 13h } 05^{\prime}\end{array}$ & ----- \\
\hline D.62 & $02 / 02 / 2001$ & $\begin{array}{l}2^{\mathrm{a}} \text { ultra-sonografia } \\
\text { (53 dias pós encarneiramento) }-12 \mathrm{~h} 56^{\prime}\end{array}$ & Parcial \\
\hline D. 157 & $08 / 05 / 2001$ & $\begin{array}{l}\text { Início das parições e pesagem dos recém-nascidos } \\
-11 \mathrm{~h} 13^{\prime}\end{array}$ & ----- \\
\hline D.201 & $19 / 06 / 2001$ & Última parição - 10h 48' & ----- \\
\hline D.217 & $07 / 07 / 2001$ & Início dos desmames e pesagens $-10 \mathrm{~h} 44^{\prime}$ & ------ \\
\hline D.259 & $18 / 08 / 01$ & Último desmame e pesagens $-11 \mathrm{~h} 10^{\prime}$ & ----- \\
\hline
\end{tabular}




\section{RESULTADOS e DISCUSSÃO}

No presente experimento, conhecendo-se e o comportamento reprodutivo dos animais Suffolk do rebanho da Cabanha Araçá, devido ao seu histórico monitorado há 17 anos, e ao comprimento do fotoperíodo na região de Valparaíso, o tratamento de indução do estro com melatonina teve início no mês de outubro, quando os animais não apresentavam sinais de estro, denotando refratariedade ao fotoperíodo crescente.

Devido a impossibilidade de dosagem de progesterona para pleno conhecimento do estado de anestro estacional, foram considerados parâmetros já evidenciados no Estado de São Paulo (RODRIGUES, 2001), que demonstraram a estacionalidade reprodutiva das raças Suffolk e Romney Marsh, através de perfil plasmático de progesterona e melatonina.

\subsection{Resposta ao Efeito Macho e Acasalamentos}

O intervalo entre o efeito macho e cios férteis não apresentou diferença significativa entre os tratamentos, apesar dos grupos tratados com melatonina apresentarem intervalos mais curtos (Tabela 4). O mesmo aconteceu com o intervalo entre o encarneiramento e os acasalamentos férteis. Considerando-se como 148 dias o padrão fisiológico de gestação da espécie ovina, e retrocedendo-se esse valor da data do parto, concluiu-se que a primeira concepção ocorreu no nono dia após o efeito macho (primeiro dia do encarneiramento) e, a última, 51 dias após o início do efeito macho. 
Tabela 4 -Intervalo entre o efeito macho (EM) e cios férteis (CF), e do encarneiramento (REP) aos acasalamentos (AC), nos grupos experimentais (1M - um implante; $2 \mathrm{M}$ - dois implantes; C - controle). Valparaíso (SP), dez 2000-jan 2001

\begin{tabular}{ccc}
\hline GRUPOS & $\begin{array}{c}\text { Intervalo } \\
\text { EM-CF }\end{array}$ & $\begin{array}{c}\text { Intervalo } \\
\text { REP - AC }\end{array}$ \\
\hline $\mathbf{1 M}$ & $20,8 \pm 10,26$ & $11,8 \pm 10,26$ \\
$\mathbf{2 M}$ & $25,0 \pm 12,75$ & $16,0 \pm 12,75$ \\
$\mathbf{C}$ & $27,0 \pm 9,68$ & $18,0 \pm 9,68$ \\
\hline
\end{tabular}

$\mathrm{Na}$ figura 4 consta a distribuição de cios férteis em relação ao momento do efeito macho e encarneiramento. Pode-se notar uma maior concentração de concepções na terceira semana pós efeito macho, entre os dias 16 a 22 de dezembro, quando 18 de 47 fêmeas se tornaram gestantes, sem diferença significativa entre os grupos.

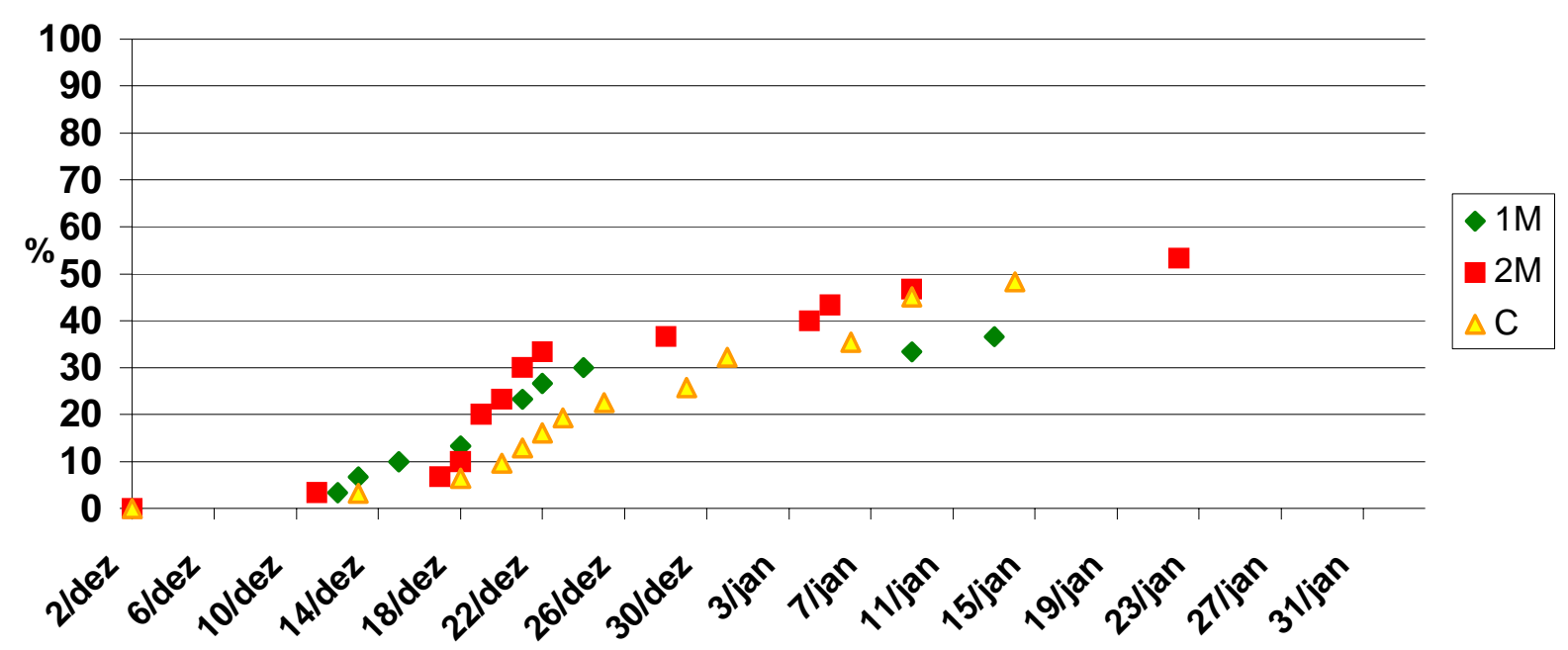

Figura 4 - Distribuição do percentual de fêmeas gestantes nos diferentes grupos experimentais, em relação ao efeito macho (02 de dezembro) e encarneiramento (11 de dezembro) (1M - um implante; $2 \mathrm{M}$ - dois implantes; C - controle) 
Esses resultados se aproximam aos de Zúñiga, Forcada e Abecia (2002) na raça Rasa Aragonesa, e aos de Haresign (1992b) na raça Mule, nos quais o tratamento com melatonina agiu positivamente na quebra da estacionalidade, com concentração de estros $26 \pm 1,9$ dias e 24,3 \pm 4,8 dias, respectivamente após 0 início do efeito macho. Em ovelhas mestiças Merino, as concepções concentraramse entre o $20^{\circ}$ e $28^{\circ}$ dia pós início do efeito macho (WILLIAMS et al., 1992) e em ovelhas Merino puras do 16 ao 25으 dia (GÓMEZ BRUNET et al., 1995).

Diferentemente do resultado deste trabalho, Kouimtzis, Belibasaki e Doney (1989) observaram um retardo de 17 dias no início da atividade reprodutiva de fêmeas não tratadas da raça Karagouniki, em relação as tratadas.

O elevado número de fêmeas controle que apresentaram ciclicidade estral talvez possa ser justificado pelo "efeito de facilitação social", proposto por Haresign (1992b) e Williams et al. (1992), e reafirmado por Zarco et al. (1995), devido a uma interação "fêmea-macho-fêmea" ou "fêmea tratada ciclando-fêmea controle". Essa interação social seria desencadeada pelo efeito macho nas fêmeas previamente tratadas com melatonina e, portanto, responsivas, e pela somatória de feromônios, masculino e feminino, interagindo e estimulando fêmeas em anestro estacional, não submetidas ao tratamento hormonal com um ou dois implantes.

Vale ressaltar o bom desempenho do reprodutor, pois a relação macho/ fêmea ficou aquém do recomendado (HARESIGN, 1992a) e mesmo assim, no período de uma semana, 18 fêmeas se tornaram gestantes. Notou-se melhora da libido, aos demais reprodutores da cabanha, também observado por Rosa, Juniper e Bryant (2000a) em reprodutores Mule tratados com implante de melatonina. Apesar de não ter sido feito um acompanhamento por exame andrológico, pode ter ocorrido uma melhora na qualidade espermática desse reprodutor, que igualmente recebeu 
implante de melatonina, favorecendo o resultado. Tal fato foi relatado por diversos autores (HANIF; WILLIAMS, 1991; KAYA et al., 2001).

Reprodutores ovinos tendem a apresentar um comportamento "seletivo", elegendo e acasalando diversas vezes a mesma fêmea, o que faz com que outras ovelhas que venham a manifestar estro no mesmo dia não sejam acasaladas (PRICE; BORGWARDT; DALLY, 2001). Tal fato pode ter ocorrido neste experimento, pois oito animais se tornaram gestantes cerca de 17 dias após a concentração de estros da terceira semana, conforme apresentado na figura 4. Chemineau et al. (1992) relataram que o tratamento com uso de melatonina exógena induz dois a três ciclos ovulatórios, o que confirma a hipótese acima.

O tratamento com melatonina no início da primavera, associado ao efeito macho, indicou ser efetivo, tanto para antecipação, como para a melhora da performance reprodutiva, indo ao encontro das afirmações de Durotoye et al. (1991), Kouimtzis, Belibasaki e Doney (1989), Sharon, Forsyth e Arendt (1992), Stellflug et al. (1994).

4.2 Gestação, Parição e Fertilidade ao tratamento de indução do estro com melatonina

Os dados relativos à taxa de gestação às ultra-sonografias, parição e fertilidade estão apresentados na tabela 5. 
Tabela 5 - Resultados relativos à taxa de gestação à primeira (1으) e segunda (2US) ultra-sonografia, taxa de parição e fertilidade ao tratamento de indução do estro com implante de melatonina. Valparaíso (SP), dez 2000 -jun 2001

\begin{tabular}{cccccc}
\hline GRUPOS & $\begin{array}{c}\text { Animais } \\
\mathrm{n}\end{array}$ & $\begin{array}{c}1 \% \text { US } \\
\%\end{array}$ & $\begin{array}{c}2 \% \text { US } \\
\%\end{array}$ & $\begin{array}{c}\text { Parição } \\
\%\end{array}$ & $\begin{array}{c}\text { Fertilidade } \\
\%\end{array}$ \\
\hline \multirow{2}{*}{$\mathbf{1 M}$} & \multirow{2}{*}{30} & 36,7 & 36,7 & 36,7 & 43,3 \\
& & $(11 / 30)$ & $(11 / 30)$ & $(11 / 30)$ & $(13 / 30)$ \\
\multirow{2}{*}{$\mathbf{M}$} & \multirow{2}{*}{30} & 43,3 & 46,7 & 53,3 & 53,3 \\
& & $(13 / 30)$ & $(14 / 30)$ & $(16 / 30)$ & $(16 / 30)$ \\
$\mathbf{C}$ & 31 & 38,7 & 48,4 & 48,4 & 51,6 \\
& \multirow{2}{*}{31} & $(12 / 31)$ & $(15 / 31)$ & $(15 / 31)$ & $(16 / 31)$ \\
\hline
\end{tabular}

No grupo $1 \mathrm{M}$, dois animais diagnosticados gestantes no primeiro exame ultra-sonográfico não mais apresentaram imagem compatível com gestação no segundo exame, realizado com intervalo de nove dias, denotando morte embrionária. Porém, duas novas gestações foram diagnosticadas ao segundo exame, mantendo o resultado anterior. No grupo C, apesar do aumento no percentual de fêmeas gestantes entre o primeiro e segundo exame ultra-sonográfico, e deste ter se mantido constante até a parição, ocorreu abortamento em uma fêmea que não havia sido diagnosticada gestante nas ultra-sonografias, dado esse acrescentado na taxa de fertilidade do grupo. Não houve perdas embrionárias ou fetais no grupo $2 \mathrm{M}$.

As três variáveis analisadas não apresentaram diferença significativa $(P \geq 0,05)$ entre os grupos, diferentemente dos resultados obtidos por Gómez Brunet et al. (1995) na raça Merino, na qual a taxa de fertilidade favoreceu os animais tratados, em relação aos não tratados.

Haresign (1992b), revelou morte embrionária de 6,3\% para animais submetidos a diferentes protocolos com implante de melatonina, valor este que se assemelha ao encontrado entre nossos grupos experimentais, que foi de 
$4,4 \%(2 / 45)$, sem diferença entre tratamentos. Considerando que o rebanho foi corretamente manejado do ponto de vista sanitário e que o início das gestações ocorreu no verão, momento de abundância de pastagens, a elevada temperatura ambiente poderia ser a causa dessa perda.

Os partos ocorreram entre 148 e 190 dias após o início do encarneiramento. Valores semelhantes (148 a 198 dias) foram encontrados em experimento entre as latitudes $39-41^{\circ} \mathrm{N}$, com animais de três raças (Merino, Merino Entrefino e Rasa Aragonesa), tratados com um implante ou testemunhas (GÓMEZ BRUNET et al., 1995). Tal fato nos revela que a maioria dos acasalamentos férteis ocorreram no terço inicial do encarneiramento, sendo que em um período de 17 dias, 26 de 45 fêmeas tornaram-se gestantes. Wheaton, Pohl e Windels (1990) verificaram que o tratamento com melatonina não influencia a duração da gestação, fato confirmado por McEvoy et al. em 1998.

A taxa de parição nos grupos $1 \mathrm{M}(36,7 \%), 2 \mathrm{M}(53,3 \%)$ e C $(48,4)$ estiveram aquém daquela relatada por Zaiem et al. (2000) em raças nativas da Tunísia, que atingiram índices superiores a $90 \%$ tanto em animais tratados quanto nos controle, e semelhante aos encontrados por Rojero et al. (2001) em animais deslanados Pelibuey do México, criados em região de precipitação pluviométrica e temperatura média próximas daquelas de Valparaíso onde foi realizado este experimento.

Resultados igualmente elevados foram encontrados por Laliotis et al. (1998) em raças leiteiras da Grécia, com taxa de parição de $83,3 \%$ para os tratados e $68,8 \%$ para os animais controle, e por Chemineau et al. (1991) em raças de corte francesas, de $85 \%$ e $76 \%$, respectivamente. Em ambos os casos, o tratamento com melatonina aumentou de forma significante a prolificidade $(p \leq 0,05)$, o que não foi por nós observado nos três grupos experimentais. 


\subsection{Prolificidade}

A taxa de prolificidade das fêmeas paridas favoreceu o grupo $2 \mathrm{M}$, com 1,50 cordeiro por fêmea (24/16), seguido pelo $1 \mathrm{M}$ com 1,36 (15/11) e pelo C, com 1,27 (19/15). A taxa de prolificidade por fêmea exposta foi de 0,8 (24/30), 0,5 (15/30) e 0,6 cordeiro/fêmea exposta (19/30) para os grupos $2 \mathrm{M}, 1 \mathrm{M}$ e C, respectivamente, sem diferença significativa entre grupos.

Abecia, Forcada e Zúñiga (2002), trabalhando com diferentes raças ovinas na Espanha, encontraram médias superiores para os animais tratados com um implante de melatonina $(1,47)$ em relação ao grupo controle $(1,34)$. No mesmo país, Gómez Brunet et al. (1995) trabalhando com a raça Merino, constataram tais diferenças, encontrando 1,15 cordeiros por fêmea tratada e 1,03 cordeiros para as não tratadas. Esse aumento significativo na prolificidade de animais tratados com melatonina foi também observados em raças francesas de corte $(1,42 \times 1,35)$ e raças leiteiras gregas $(1,48 \times 1,31)$, o que pode ser atribuído ao efeito luteotrófico desse hormônio, conforme sugerido por Gómez Brunet et al. (1995), mas que não foi observado em nossos grupos experimentais.

Em Minessota, pesquisa com ovelhas mestiças Suffolk apresentou taxa de prolificidade idêntica $(1,8)$ para animais tratados com um implante de melatonina e animais controle (WHEATON; POHL; WINDELS, 1990), e superior aos nossos resultados em fêmeas puras da mesma raça.

Tratamento semelhante ao empregado em nosso experimento foi utilizado em 551 ovelhas puras e mestiças Suffolk, em rebanhos do Reino Unido, e verificado um aumento de 0,08 cordeiros, para animais tratados com $18 \mathrm{mg}$ de melatonina e 0,20 cordeiros para animais tratados com $36 \mathrm{mg}$, sem diferença significativa entre 
tratamentos (HARESIGN; PETERS; STAPLES, 1990), mas que semelhante ao nosso experimento, resulta em maior número de cordeiros nascidos em fêmeas tratadas com dois implantes.

A figura 5 apresenta os resultados de gemelaridade por grupo experimental, com maior percentual de partos duplos no grupo $2 \mathrm{M}(50 \%$ - 8/16) e de partos simples nos grupos $1 \mathrm{M}(64 \%$ - $7 / 11)$ e controle $(73 \%$ - 11/15), sem diferença significativa entre grupos. Da mesma maneira, Williams et al. (1992) e Rekik, Bryant e Cunningham (1991) encontraram maior gemelaridade para ovelhas tratadas com implante de melatonina $(37,2 \%$ e $76,93 \%$, respectivamente), do que as controle (24\% e 35,72\%, respectivamente), o que Haresign (1992b) e Wallace et al. (1988), atribuíram ao efeito significante da melatonina na taxa de ovulação.

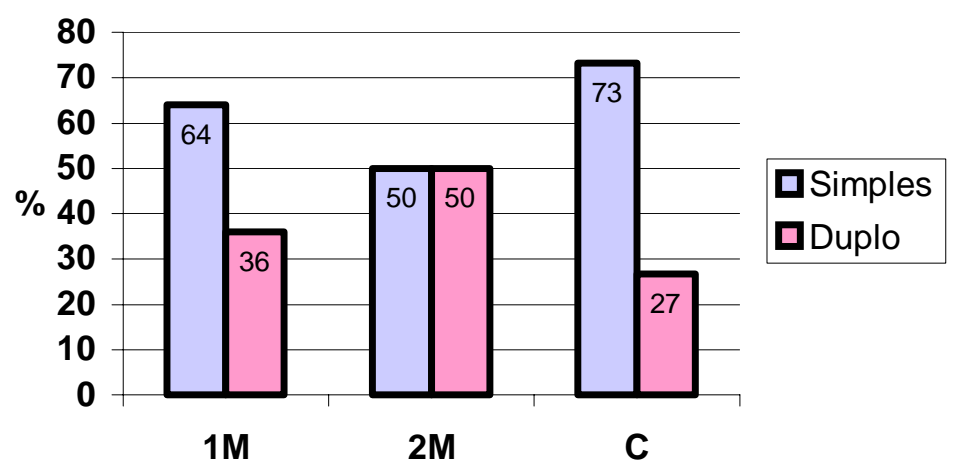

Figura 5 - Distribuição da percentagem de partos simples e gemelares, por grupo experimental ( $\mathrm{C}$ - controle; $1 \mathrm{M}$ - um implante; $2 \mathrm{M}$ - dois implantes)

O aumento na prolificidade encontrado por pesquisadores franceses se deu pelo aumento de partos gemelares, e não triplos ou quádruplos, o que ocorre em tratamentos de indução do estro com o uso de progestágenos e eCG. Tais autores também ressaltaram a vantagem do tratamento quanto a significante redução no período de nascimentos (CHEMINEAU et al., 1992). 
Neste trabalho com fêmeas da raça Suffolk não ocorreram partos triplos ou quádruplos, o que não é desejado pelos produtores, devido ao baixo peso dos cordeiros em gestações com número excessivo de fetos.

\subsection{Proporção Sexual}

Os três grupos experimentais apresentaram maiores percentuais de nascimento do sexo feminino, uma média de 55,2\% (32/58) de fêmeas e 44,8\% (26/58) de machos. A proporção de 1:1,23 difere do resultado encontrado por Williams et al. (1992) em ovelhas mestiças Merino, de 1:0,63. Essa variável não depende dos tratamentos aplicados, e não apresentou diferença significativa entre grupos.

\subsection{Peso das crias ao nascimento e desmame}

O peso médio dos cordeiros foi de $4,53 \pm 0,86 \mathrm{Kg}$, e o das cordeiras de 4,28 \pm 0,73Kg. Segundo Durotoye et al. (1991) e McEvoy et al. (1998), o peso é uma variável independente dos tratamentos.

Entretanto, foi dispensada uma atenção especial à esse parâmetro devido a época do ano em que ocorreram as parições. Por se tratar de um programa de indução de estro, essas ocorreram no outono, momento de diminuição da qualidade das pastagens. Por esse motivo as matrizes foram suplementadas, sendo tal manejo indicado no terço final de gestação, visando evitar a ocorrência de distúrbio metabólico (toxemia da gestação) e perda dos cordeiros. 
Dessa forma, as médias foram acima do esperado para nascimentos nessa época do ano, sendo que, na Califórnia, experimento com a raça Suffolk em animais encarneirados na estação de monta natural, obteve média de $4,9 \mathrm{Kg}$ por recém-nascido (QUIRKE; STABENFELDT; BRADFORD, 1985).

Os cordeiros foram suplementados com concentrado através do uso de "creep feeding" e, desmamados aos 60 dias, apresentaram peso médio de $28,36 \pm 2,03 \mathrm{Kg}$ para os machos e $27,19 \pm 1,55$ para as fêmeas.

Atravessando a puberdade com abundância de pastagens de primavera e verão, as borregas atingiram o peso adequado para acasalamento ( $70 \%$ do peso de fêmeas adultas da raça) aos 12 meses de idade e os machos jovens puderam ser utilizados como reprodutores.

O uso desse implante a campo poderá trazer uma alternativa para o produtor, com a finalidade de incrementar a produção de carne ovina, aumentando a demanda e oferta para o mercado nacional, em plena ascensão. Outro intuito do uso desse implante em nosso país é de viabilizar a utilização de produtos nascidos durante a estação reprodutiva de outono (maio a julho), na estação de monta natural subseqüente, o que foi atingido com pleno êxito neste trabalho com a raça Suffolk. 


\section{CONCLUSÃO}

Não houve diferença entre as variáveis estudadas em decorrência do uso de implantes subcutâneos de melatonina.

Nestas condições experimentais fêmeas ovinas da raça Suffolk apresentaram estro e tornaram-se gestantes durante a contra estação reprodutiva. 


\section{REFERÊNCIAS}

ABECIA, J. A; FORCADA, F.; ZÚÑIGA, O. The effect of melatonin on the secretion of progesterone in sheep and on the development of ovine embryos in vitro. Veterinary Research Communications, v. 26, p. 151-158, 2002.

ARENDT, J. Melatonin and the mammalian pineal gland. London: Chapman \& Hall ,1995. $331 \mathrm{p}$.

ARENDT, J.; SYMONS, A. M.; LAUD, C. A.; PRYDE, S. J. Melatonin can induce early onset of breeding season in ewes. Journal of Endocrinology, v. 97, p. 395400, 1983.

BARRET, P.; SCHUSTER, C.; MERCER, J.; MORGAN, P. J. Sensitization: a mechanism for melatonin action in the pars tuberalis, Journal of

Neuroendocrinology, v. 15, p. 415-421, 2003.

BITTMAN, E. L.; DEMPSEY, R. J.; KARSCH, F. J. Pineal melatonin secretion drives the reproductive response to daylight in the ewe. Endocrinology, v. 113, p. 22762283, 1983.

BRONSON, F. H. Mammalian reproductive strategies: genes, photoperiod and latitude. Reproduction Nutrition Development, v. 28, p. 335-347, 1988.

BRZEZINSKI, A. Melatonin in Humans. The New England Journal of Medicine, v. 16, p. 186-195, 1997.

CARLES, A. B.; KIPNGENO, W. A. K. The effect of season and the introduction of rams on oestrous activity in Somali, Nandi, Merino, Karakul and New Zeland Romney Marsh ewes in Kenya. Animal Production, v. 43, p. 447-457, 1986.

CHEMINEAU, P.; VANDAELE, E.; BRICE, G.; JARDON, C. Utilization des implantes de malatonin pour l'amélioration des performances de reproduction chez la brebis. Recueil de Médicine Vétérinaire, v. 167, n. 3-4, p. 227-239, 1991. 
CHEMINEAU, P.; MALPAUX, B.; DELGADILLO, J. A.; GUÉRIN, Y.; RAVAULT, J. P.; THIMONIER, J.; PELLETIER, J. Control of sheep and goat reproduction: use of light and melatonin. Animal Reproduction Science, v. 30, p. 157-184, 1992.

CHEMINEAU, P.; MALPAUX, J.; PELLETIER, J.; LEBOEUF, B.; DELGADILLO, J. A.; DELETANG, F.; POBEL, T.; BRICE, G. Emploi des implants de mélatonine et des traitements photopériodiques pour maîtriser la reproduction saisonnières chez lês ovins et les caprins. INRA Production Animale, v. 9, n. 1, p.45-60, 1996.

DUROTOYE, L. A.; RAJKUMAR R.; ARGO C. M.; NOWAK R.; WEBLEY G. E.; MCNEIL M. E.; GRAHAM N. B.; RODWAY R. G. Effect of constant-release melatonin implants on the onset of oestrous activity and on reproductive performance in the ewe. Animal Production, v. 52, n. 3, p. 489-497, 1991.

ENGLISH, J.; POULTON, A. L.; ARENDT, J., SYMONS, A. M. A comparison of the efficiency of melatonin treatments in advancing oestrus in ewes. Journal Reproduction Fertility, v. 77, p. 321-327, 1986.

FORCADA, F.; ZARAZAGA, L.; ABECIA, J. A. Effect of exogenous melatonin and plane of nutrition after weaning on estrous activity, endocrine status and ovulation rate in Salz ewes lambing in the seasonal anestrus. Theriogenology, v. 43, p. 11791193, 1995.

FORCADA, F.; ZÚÑIGA, O.; ABECIA, J. A. The role of nutrition in the regulation of $\mathrm{LH}$ secretion during anestrus by the serotoninergic and dopaminergic systems in Mediterranean ewes treated with melatonin. Theriogenology, v. 58, p. 1303-1313, 2002.

GANGULY, S.; COON, S. L.; KLEIN, D. C. Control of melatonin synthesis in the mammalian pineal gland: The critical role of serotonin acetylation. Cell and Tissue Research, v. 309, p. 127-137, 2002.

GÓMEZ BRUNET, A.; LÓPEZ SEBASTIAN, A.; PICAZP, R. A.; CABELLOS, B.; GODDARD, $S$. Reproductive response and $\mathrm{LH}$ secretion in ewes treated with melatonin implants and induced to ovulate with the ram effect. Animal Reproduction Science, v. 39, p. 23-34, 1995.

GÓMEZ BRUNET, A.; MALPAUX, B.; DAVEAU, A.; TARAGNAT, C.; CHEMINEAU, $P$. Genetic variability in melatonin secretion originates in the number of pinealocytes in sheep. Journal of Endocrinology, v. 172, p. 397-404, 2002. 
HANIF, M.; WILLIAMS, L. The effects of melatonin and light treatment on the reproductive performance of yearling Sulffolk rams. British Veterinary Journal, v. 147, p. 49-56, 1991.

HARESIGN, W., PETERS, A. R.; STAPLES, L. D. The effects of melatonin on the implants on breeding activity and litter size in commercial sheep flocks in the UK. Animal Production, v. 50, p. 111-121, 1990.

HARESIGN, W. Responses of ewes to melatonin implants: importance of the interval between treatment and ram introduction on the synchrony of mating, and effects on ovulation rate. Animal Production, v. 54, n. 1, p. 41-45, 1992a.

HARESIGN, W. The effect of implantation of lowland ewes with melatonin on the time of mating and reproductive performance. Animal Production, v. 54, p. 31-39, 1992b.

HARUMI, T.; MATSUSHIMA, S. Separation and assay methods for melatonin and its precursors. Journal of Chromatography B, v. 747, p. 95-110, 2000.

HAZLERIGG, D. G. What is role of melatonin within the anterior pituitary? Journal of Endocrinology, v. 170, p. 493-501, 2001.

JORDAN, B. T.; HANRAHAN, J. P.; ROCHE, J. F. The effect of melatonin implantation in the middle of the breeding season on the subsequent reproductive activity of Scottish Blackface ewes. Animal Reproduction Science, v. 23, p. 41-48, 1990.

KARSCH, F. J.; BITTMAN, E. L.; FOSTER, D. L.; GOODMAN, R. L.; LEGAN, S. J.; ROBINSON, J. E. Neuroendocrine basis of seasonal reproduction. Recent Progress in Hormone Research, v. 40, p. 185-232, 1984.

KAULFUSS, K.; MAY, J.; SUSS, R.; MOOG, U. In vivo diagnosis of embryo mortality in sheep by real-time ultrasound. Small Ruminant Research, v. 24, p. 141-145, 1997.

KAYA, A.; AKSOY, M. ; BASPINAR, N.; YILDIZ, C.; ATAMAN, M. B. Effect of melatonin implantation to sperm donor rams on post-thaw viability and acrosomal integrity of sperm cells in the breeding and non-breeding season. Reproduction in Domestic Animals, v. 36, p. 211-215, 2001. 
KENNAWAY, D. J., DUNSTAN, E. A.; STAPLES, L. D. Photoperiodic control of the onset of breeding activity and fecundity in ewes. Journal Reproduction Fertility, v. 80 , n. 34, p. 1-13, 1987.

KENNAWAY, D. J., GILMORE, T. A.; SEAMARK, R. F. Effect of melatonin feeding on serum prolactin and gonadotropin levels and the onset of seasonal estrous cyclicity in sheep. Endocrinology, v. 110, n. 5, p. 119-127, 1982.

KLEIN, D.C.; COON, S.; ROSEBOOM, P. H; WELLER, J. L.; BERNARD, M.; GASTEL, J. A.; ZATZ, M.; IUVONE, P. M.; RODRIGUEZ, I. R.; BÉGAY, V.; FALCÓN, J.; CAHILL, G. M.; CASSONE, V. M.; BALER, R. The melatonin rhythm generating enzyme: molecular regulation of serotonina $\mathrm{N}$-acetiltransferase in the pineal gland. Recent Progress in Hormone Research, v. 52, p. 307-357, 1997.

KNIGHT, T. W.; TERVIT, H. R.; FAIRCLOUGH, R. J. Corpus luteum function in ewes stimulated by rams. Theriogenology, v. 15, n. 2, p. 183-190, 1981.

KOUIMTZIS, S. A.; BELIBASAKI, S.; DONEY, J. M. Melatonin advances and condenses the onset of seasonal breeding in Greec dairy ewes. Animal Production, v. 48 , p. 399-405, 1989.

LALIOTIS, V.; VOSNIAKOU, A.; ZAFRAKAS, A.; LYMBEROPOULOS, A.; ALIFAKIOTIS, T. The effect of melatonin on lambing and little size in milking ewes after advancing the breeding season with progestágeno and PMSG followed by artificial insemination. Small Ruminant Research, v. 31, p. 79-81, 1998.

LIMA, M. C. C. Aspectos ultra-sonográficos e aspectos hormonal da gestação ovina (Ovis aires) nas raças Bergamácia e Ideal. 2000. 129 p. Tese (Doutorado) Faculdade de Medicina Veterinária e Zootecnia, Universidade Estadual Paulista, Botucatu, 2000.

LINCON, G. A.; SHORT, R. V. Seasonal breeding: nature's contraceptive. Recent Progress in Hormone Research, v. 36, p. 1-52, 1980.

MALPAUX, B.; ROBINSON, J. E.; BROWN, M. B.; KARSCH, F. J. Importance of changing photoperiod and melatonin secretory pattern in determining the length of the breeding season in the Suffolk ewe. Journal of Reproduction Fertility, v. 83, n. 1, p. 461-470, 1988. 
MALPAUX, B.; VIGUIÉ, C.; SKINNER, D. C.; THIÉRY, J. C.; PELLETIER, J.; CHEMINEAU, P. Seasonal breeding in sheep: Mechanism of action of melatonin. Animal Reproduction Science, v. 42, p. 109-117, 1996.

MALPAUX, B.; VIGUIE, C.; SKINNER, D. C.; THIERY, J. C.; CHEMINEAU, P. Control of the circannual rhythm of reproduction by melatonin in the ewe. Brain Research Bulletin, v. 44, n. 4, p. 431-438, 1997.

MCEVOY, T. G.; ROBINSON, J. J.; AITKEN, R. P.; ROBERTSON, I. S. Melatonin treatment of embryo donor and recipient ewes during anestrus affects their endocrine status, but not ovulation rate, embryo survival or pregnancy. Theriogenology, v. 49, n. 5, p. 943-955, 1998.

MCMILLAN, R. W.; SEALEY, R. C. Do melatonin implants influence the breeding season in Coopworth ewes? Proceedings New Zealand Society of Animal Production, v. 49, p. 109-111, 1989.

NETT, T.M.; NISWENDER, G. D. Influence of exogenous melatonin on seasonality of reproduction in sheep. Theriogenology, v. 17, p. 645- 653, 1982.

NOËL, B.; MANDIKI, S .M. N.; PERRAD, B.; BISTER, J. L.; PAQUAY, R. Terminal follicular growth, ovulation rate and hormonal secretion after melatonin pretreatment prior to FGA-PMSG synchronization in Suffolk ewes at the onset breeding season. Small Ruminant Research, v. 32, p. 269-277, 1999.

NOWAK, R.; RODWAY, R. G. Length of melatonin exposure and onset of ovarian activity in anoestrous ewe. Journal Reproduction Fertility, v. 80, p. 343-347, 1987.

O'CALLAGHAN, D.; KARSCH, F. J.; BOLAND, M. P.; ROCHE, J. F. What photoperiodic signal is provided by a continuos-release melatonin implant? Biology of Reproduction, v. 45 p. 927-933, 1991.

O'CALLAGHAN, D.; SWEENEY, T.; TAYLOR, L.; ROBLOT, G.; WYLDE, R. Domestic Animal Endocrynology, v. 16, n. 4, p. 207-217, 1999.

OLDHAM, C. M.; MARTIN, G. B. Stimulation of seasonally anovular Merino ewes by rams: II Premature regression of ram-inducec corpora lutea. Animal Reproduction Science, v. 1, p. 283-290, 1978. 
OLDHAM, C. M.; MARTIN, G. B.; KNIGHT, T. W. Stimulation of seasonally anovular Merino ewes by rams: I Time from introduction of the rams to the preovulatory LH surge and ovulation. Animal Reproduction Science, v. 1, p. 283-290, 1978.

PERKINS, A.; FITZGERALD, J. A. The behavioral component of the ram effect: The influence of ram sexual behavior on the induction of estrus in anovulatory ewes. Journal Animal Science, v. 72, p. 51-55, 1994.

POULTON, A. L.; ENGLISH, J.; SYMONS, A. M.; ARENDT, J. Effects of various melatonin treatments on plasma prolactin concentration in the ewe. Journal of Endocrinology , v. 108, p. 287-292, 1986.

POULTON, A. L.; SYMONS, A. M.; KELLY, M. I.; ARENDT, J. Intraruminal soluble glass boluses containing melatonin can induce early onset activity in ewes. Journal Reproduction Fertility, v. 80, p. 235-239, 1987.

PRICE, E. O.; BORGWARDT, R. E.; DALLY, M. R. Male-male competition fails to sexually stimulate domestic rams. Applied Animal Behaviour Science, v. 74, p. 217-222, 2001.

QUIRKE, J. F.; STABENFELDT, G. H.; BRADFORD, G. E. Onset of puberty and duration of the breeding season in Suffolk, Rambouillet, Finnish Landrace, Dorset and Finn-Dorset ewe lambs. Journal of Animal Science, v. 60, p. 1463-1471, 1985.

REITER, R. J. Pineal melatonin: cell biology of its synthesis and of its physiological interactions. Endocrine Reviews, v. 12, p. 151-180, 1991.

REKIK, M.; BRYANT, M. J.; CUNNINGHAM, F. J. Effects of treatment with melatonin on the response of seasonally anovular ewes to the introduction of rams. Animal Production, v. 53, n. 2, p. 203-207, 1991.

REKWOT, P. I.; OGWU, D.; OYEDIPE, E. O.; SEKONI, V. O. The role of pheromones and biostimulation in animal reproduction. Animal Reproduction Science, v. 65, n. 3-4, p. 157-170, 2001.

ROBINSON, J. J.; WIGZELL, S.; AITKEN, R. P.; WALLACE, J. M.; IRELAND, S.; ROBERTSON, I. S. The modifying effects of melatonin, ram exposure and plane of nutrition on the onset of ovarian activity, ovulation rate and the endocrine status of ewes. Animal Reproduction Science, v. 26, n. 1-2, p. 73-91, 1991. 
ROBINSON, J. J.; WIGZELL, S.; AITKEN, R. P.; WALLACE, J. M.; IRELAND, S.; ROBERTSON, I. S. Daily oral administration of melatonin from March onwards advances by 4 months the breeding season of ewes maintained under the ambient photoperiod at 57N. Animal Reproduction Science, v. 27, n. 2-3, p. 141-160, 1992.

RODRIGUES, P. A. Avaliação da sazonalidade reprodutiva e perfil secretório de melatonina em ovelhas (Ovis aries) das raças Romney Marsh, Suffolk e Santa Inês. 2001. 82 p. Tese (Doutorado) - Faculdade de Medicina Veterinária e Zootecnia, Universidade Estadual Paulista, Botucatu, 2001.

RODWAY, R. G.; RAJKUMAR, R. R.; NOWAK, R.; WARD, S. J.; ARGO, C. M. The use of vaginally administered melatonin in the manipulation of the breeding season in ewes. British Society of Animal Production, v. 146, n. 1, p. 17-23, 1990.

ROJERO, R. D. M.; QUINTERO, L. A. Z.; GUTIÉRREZ, I. R.; LAZO, C.C.; MÉNDEZ, J. V. Efecto de los implantes subcutáneos de melatonina y la suplementación alimentaria, sobre la inducción de la actividad ovárica en ovejas Pelibuey durante la época de anestro. Veterinaria México, v. 32, n. 4, p. 237-247, 2001.

RONDON, Z.; FORCADA, F.; ZARAZAGA, L.; ABECIA, J. A.; LOZANO, J. M. Oestrous activity, ovulation rate and plasma melatonin concentrations in Rasa Aragonesa ewes maintained at two different and constant body condition score levels and implanted or reimplanted with melatonin. Animal Reproduction Science, v. 41, n. 3-4, p. 225-236, 1996.

ROSA, H. J. D.; JUNIPER, D. T.; BRYANT, M. J. The effects of exposure to oestrous ewes on rams sexual behaviour, plasma testosterone concentration and ability to stimulate ovulation in seasonally anoestrous ewes. Applied Animal Behaviour Science, v. 67, p. 293-305, 2000a.

ROSA, H. J. D.; JUNIPER, D. T.; BRYANT, M. J. Effects of recent sexual experience and melatonin treatment of rams on plasma testosterone concentration, sexual behaviour and ability to induce ovulation in seasonally anoestrous ewes. Journal Reproduction Fertility, v. 120, p. 169-176, 2000b.

SAS. SAS user's guide statistics. Cary: 5. ed. Statistical Analysis System Institute, 1985. 1 CD-ROM.

SELMAOUI, B.; OGUINE, A.; THIBAULT, L. Food access schedule and diet composition alter rhythmicity of serum melatonin and pineal NAT activity. Physiology and Behavior, v. 74, p. 449-455, 2001. 
SHARON L. D.; FORSYTH, I. A.; ARENDT, J. Induced out-of-season breeding in British Saanen dairy goats: use of artificial photoperiods and/or melatonin administration. Animal Reproduction Science, v. 29, p. 1-15, 1992.

STAPLES, L. D.; MCPHEE, S.; KENNAWAY, D. J.; WILLIAMS, A. H. The influence of exogenous melatonin on the seasonal patterns of ovulation and oestrus in sheep. Animal Reproduction Science, v. 30, p.185-223, 1992.

STELLFLUG, J. N.; FITZGERALD, J. A.; PARKER, C. F. Effect of melatonin and extended light on reproductive performance of fall born Polypay ewe lambs and ewes during spring breeding. Theriogenology, v. 32, n. 6, p. 995-1006, 1989.

STELLFLUG, J. N.; RODRIGUEZ, F.; LAVOIE, V. A.; GLIMP, H. Á. Influence of simulated photoperiod alteration and induced estrus on reproductive performance of spring-born Columbia and Targhee ewe lambs. Journal of Animal Science, v. 72, n. 1, p. 29-33, 1994.

SWEENEY, T.; O'CALLAGHAN, D. Breeding season and ovulation rate in ewes treated with long days in spring followed by a melatonin implant and exposure to a ram. Animal Science, v. 62, n. 3, p. 507-512, 1996.

THIERY, J. C.; CHEMINEAU, P.; HERNANDEZ, X.; MIGAUD, M.; MALPAUX, B. Neuroendocrine interactions and seasonality. Domestic Animal Endocrinology, v. 23, p. 87-100, 2002.

THIMONIER, J. Photopériode et reproduction. INRA Production Animale, v. 9, n. 1, p. 3-8, 1996.

TOSINI, G.; FUKUHARA, C. Photic and circadian regulation of retinal melatonin in mammals. Journal of Neuroendocrinology, v. 15, p. 364-365, 2003.

TOSINI, G.; FUKUHARA, C. The mammalian retina as a clock. Cell Tissue Research, v. 309, p. 119-126, 2002.

TRALDI, A. S. Técnicas para otimizar o desempenho reprodutivo de cabras leiteiras. In: MATTOS, W. R. S. A produção animal na visão dos brasileiros. Piracicaba: FEALQ, 2001. p. 474-483. 
TRICOIRE, H.; LOCATELLI, A.; CHEMINEAU, P.; MALPAUX, B. Melatonin enters the cerebrospinal fluid through the pineal recess. Endocrinology, v. 143, p. 84-90, 2002.

WALLACE, J. M.; ROBINSON, J. J.; WIGZELL, S.; AITKEN, R. P. Effects of melatonin on the peripheral concentrations of $\mathrm{LH}$ and progesterone after oestrus and on conception rate in ewes. Journal of Endocrinology, v. 119, p. 523-530, 1988.

WHEATON, J. E.; POHL, H. A.; WINDELS, H. F. Effects of melatonin and progesterone administered to ewes in spring and summer. Journal of Animal Science, v. 68, n. 4, p. 923-930, 1990.

WIGZELL, S.; ROBINSON, J. J.; AITKEN, R. P.; MCKELVEY, W. A. C. Effect of the oral administration of melatonin at two times of the year on ovarian activity in ewes. Animal Production, v. 42, p. 448-449, 1986.

WIGZELL, S.; ROBINSON, J. J.; AITKEN, R. P.; MCKELVEY, W. A. C. The effect of the administration of melatonin at two times of the year on ovarian activity in ewes.

British Society of Animal Production, v. 146, n. 1, p. 17-23, 1990.

WILLIAMS, A. H.; MCPHEE, S. R.; REEVE, J. L.; STAPLES, L. D. Optimum use of subcutaneous melatonin implants to enhance the reproductive performance of seasonal and non-seasonal sheep joined in spring and early summer. Animal Reproduction Science, v. 30, p. 225-258, 1992.

WILLIAMS, L. M.; HELLIWELL, R. J. A. Melatonin and seasonality in the sheep. Animal Reproduction Science, v. 33, n. 1-4, p. 159-182, 1993.

WITT-ENDERBY, P. A.; LI, P. K. Melatonin receptors and ligands, Vitamins and Hormones, v. 58, p. 321-354, 2000.

ZAIEM, I.; CHEMLI, J.; SLAMA, H.; TAINTURIER, D. Amélioration des performances de reproduction par l'utilisation de la mélatonine chez la brebis à contre saison en Tunisie. Revue de Médicine Vétérinaire, v. 151, p. 517-522, 2000.

ZARCO, L.; RODRIGUEZ, E. F.; ANGULO, M. R. B.; VALENCIA, J. Female to female stimulation of ovarian activity in ewe. Journal Reproduction Science, v. 39, p. 251-258, 1995. 
ZÚÑIGA, O.; FORCADA, F.; ABECIA, J. A. The effect of melatonin implants on the response to the male effect and on the subsequent cyclicity of Rasa Aragonesa ewes. Animal Reproduction Science, v. 72, p. 165-174, 2002. 